\title{
Article
}

\section{Study of Sorption Kinetics and Sorption-Desorption Models to Assess the Transport Mechanisms of 2,4-Dichlorophenoxyacetic Acid on Volcanic Soils}

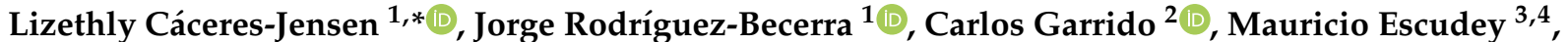 \\ Lorena Barrientos $^{5,6} \mathbb{D}^{\mathbb{D}}$, Jocelyn Parra-Rivero ${ }^{1}$, Valentina Domínguez-Vera ${ }^{1}$ and Bruno Loch-Arellano ${ }^{1,7}$
}

1 Laboratorio de Fisicoquímica \& Analítica (PachemLab), Departamento de Química, Facultad de Ciencias Básicas, Universidad Metropolitana de Ciencias de la Educación, Santiago 7760197, Chile; jorge.rodriguez@umce.cl (J.R.-B.); joselyn.parrarivero@gmail.com (J.P.-R.); valentina.dominguez@umce.cl (V.D.-V.); loch.arellano@gmail.com (B.L.-A.)

2 Laboratorio de Química Inorgánica, Departamento de Química, Facultad de Ciencias Básicas, Universidad Metropolitana de Ciencias de la Educación, Santiago 7760197, Chile; carlos.garrido@umce.cl

3 Facultad de Química y Biología, Universidad de Santiago de Chile, Santiago 9170020, Chile; mauricio.escudey@usach.cl

4 Center for the Development of Nanoscience and Nanotechnology (CEDENNA), Santiago 9170020, Chile

check for updates

Citation: Cáceres-Jensen, L.; Rodríguez-Becerra, J.; Garrido, C.; Escudey, M.; Barrientos, L.;

Parra-Rivero, J.; Domínguez-Vera, V.; Loch-Arellano, B. Study of Sorption Kinetics and Sorption-Desorption Models to Assess the Transport Mechanisms of

2,4-Dichlorophenoxyacetic Acid on Volcanic Soils. Int. J. Environ. Res. Public Health 2021, 18, 6264.

https://doi.org/10.3390/ijerph18126264

Academic Editors: Bozena Smreczak, Alicja Kicinska and Eleonora Wcisło

Received: 15 April 2021

Accepted: 27 May 2021

Published: 9 June 2021

Publisher's Note: MDPI stays neutral with regard to jurisdictional claims in published maps and institutional affiliations.

Copyright: (c) 2021 by the authors. Licensee MDPI, Basel, Switzerland. This article is an open access article distributed under the terms and conditions of the Creative Commons Attribution (CC BY) license (https:/ / creativecommons.org/licenses/by/ $4.0 /)$.
5 Centro de Investigación en Nanotecnología y Materiales Avanzados (CIEN-UC), Facultad de Química, Pontificia Universidad Católica de Chile, Santiago 7820436, Chile; lbarrientop@uc.cl

6 Millenium Nuclei on Catalytic Processes towards Sustainable Chemistry (CSC), Santiago 7820436, Chile

7 Facultad de Ciencias, Universidad de Chile, Santiago 7800003, Chile

* Correspondence: lyzethly.caceres@umce.cl; Tel.: +56-9-87942118; Fax: +56-2-27529918

Abstract: The sorption behavior of 2,4-dichlorophenoxyacetic acid (2,4-D) in the abundant agricultural volcanic ash-derived soils (VADS) is not well understood despite being widely used throughout the world, causing effects to the environment and human health. The environmental behavior and risk assessment of groundwater pollution by pesticides can be evaluated through kinetic models. This study evaluated the sorption kinetics and 2,4-D sorption-desorption in ten VADS through batch sorption experiments. Differences in the sorption extent for the fast and slow phases was observed through the IPD model where 2,4-D sorption kinetics was controlled by external mass transfer and intra organic matter diffusion in Andisols $\left(C_{1} \neq 0\right)$. We confirmed from the spectroscopic analysis that the carboxylate group directly drives the interaction of 2,4-D on Andisol soil. The MLR model showed that $I E P, F e_{D C B}$, and $p H \times$ Silt are important soil descriptors in the 2,4-D sorption in VADS. The Freundlich model accurately represented sorption equilibrium data in all cases $\left(K_{f}\right.$ values between 1.1 and $24.1 \mu \mathrm{g}^{1-1 / \mathrm{n}} \mathrm{mL}^{1 / \mathrm{n}} \mathrm{g}^{-1}$ ) with comparatively higher sorption capacity on Andisols, where the highest hysteresis was observed in soils that presented the highest and lowest $O C$ content (H close to 0 ).

Keywords: herbicides; variable-charge-soils; sorption mechanism; sorption kinetics models; spectroscopic analysis

\section{Introduction}

Herbicide contamination of surface and groundwater is a major concern due to the widespread use of these chemicals in agricultural and urban areas and the decline in biodiversity [1]. 2,4-Dichlorophenoxyacetic acid (2,4-D) is a selective, post-emergence ionizable herbicide developed by the Dow company, corresponding to a formulation broadly used widely around the world to control annual and perennial herbs in pastures, fruits, cereals, hay, wheat, maize, barley cultivation, sorghum, sugar cane, and rice [2-4]. The relative persistence and mobility of the said herbicide are of global public concern over the potential of 2,4-D and its primary metabolites to contaminate groundwater [4] and the effects at the ecosystem level because rice production relies heavily on ample water 
supply [5]. The World Health Organization has classified 2,4-D as "probably carcinogenic to humans". The highest level of 2,4-D allowed in drinking water is $0.07 \mathrm{mg} \mathrm{L}^{-1}$ [6]. The potential health effects from ingestion of water range from physiological abnormalities and carcinogenesis.

The leaching of 2,4-D has been documented from soil to water sources due to its high use, persistence, polarity, and low sorption [2,3]. In this regard, 2,4-D sorption to soil may significantly affect the environment's eventual fate [4]. Hence, it is important to elucidate the kind of interaction of 2,4-D with the soil, where the risk of groundwater contamination with 2,4-D in different types of soil could vary. Furthermore, the soil physicochemical properties and the forms of 2,4-D found in most soils ( $p H_{\text {soil }}$ between 4 and 8 ) due to its acidic carboxyl group $\left(p K_{a}=2.8\right)$ will mediate the soil interactions of the said herbicide based on different biogeochemical and ecosystem processes.

Volcanic ash-derived soils (VADS) are relevant in economies relying on forestry and agricultural exports [7-12] of countries in Asia, Africa, Oceania, and America [7,8]. The VADS in Chile accounts for $69 \%$ of its arable land [13-16], where agriculture is developed in the central region (from $19^{\circ}$ to $56^{\circ} \mathrm{S}$ latitude). Among the VADS, Andisols and Ultisols are the most abundant in that region; at the same time, the Chilean National Agriculture and Livestock Services (SAG) indicates that 2,4-D is one of the most widely sold herbicides in that country [17]. Therefore, understanding the behavior 2,4-D in VADS and its potential risk of leaching into groundwater is essential for human health [18]. Furthermore, it is vital to be able to timely evaluate their sensitivity to anthropogenic alterations such as the use of herbicides $[19,20]$, given the economic value of these soils of high quality.

Time-dependent sorption (or non-ideal sorption) can result from physical or chemical non-equilibrium [21]. Regarding the ionizable herbicide sorption behavior in VADS, sorption kinetic is a non-equilibrium process [1,12,21-23]. In general, non-equilibrium sorption has been attributed to diffusive mass transfer (MT) resistances, non-linearity in sorption isotherms, positive hysteresis, and rate-limited sorption reactions [21]. The intra organic matter diffusion (IOMD) has been suggested to be the predominant factor responsible for the chemical non-equilibrium sorption of non-ionic or hydrophobic compounds and it can occur during pesticide transport in soils [24].

Considering the widespread use of 2,4-D in agriculture, its effects on human health and the scarce reports on 2,4-D sorption behavior in VADS, the aims of this work were (i) to establish 2,4-D sorption kinetics in ten different agricultural VADS from Chile; (ii) to apply solute transport mechanism models involved in 2,4-D sorption on VADS; (iii) to establish the 2,4-D sorption-desorption on VADS; (iv) to explore possible 2,4-D sorption mechanisms in VADS by mean of spectroscopic analysis; and (v) to identify important soil descriptors in the 2,4-D sorption on VADS by means of the MLR model. The fulfilment of these aims serves to elucidate the 2,4-D environmental behavior and the potential environmental consequences.

\section{Materials and Methods}

\subsection{Soil Samples}

The VADS were collected from the 0 to $15-\mathrm{cm}$ layer in southern-central Chile's agricultural regions (Table 1). The Walkley-Black method was used to determine the soil OC content [25]. The Blake method was used to determine the cation exchange capacity (CEC) [26]. $p H$ was measured in soil suspensions with a soil to water ratio of 1:2.5 $(w / v)$. The isoelectric point (IEP) was determined by means of electrophoretic measurements. The mineralogy and chemical composition of these soils have been previously described [27]. 
Table 1. Classification and location of volcanic ash-derived soils used in this study.

\begin{tabular}{ccc}
\hline Soil & Classification & Location \\
\hline COLL & Fine, Mesic, Xeric, Paleumult & $36^{\circ} 58^{\prime} \mathrm{S} ; 72^{\circ} 09^{\prime} \mathrm{W}$ \\
MET & Fine, Mesic, Paleumult & $38^{\circ} 34^{\prime} \mathrm{S} ; 72^{\circ} 22^{\prime} \mathrm{W}$ \\
FRE & Medial, Mesic, Xeric, Placandept & $38^{\circ} 57^{\prime} \mathrm{S} ; 72^{\circ} 36^{\prime} \mathrm{W}$ \\
STB & Ashy, Medial, Mesic, Typic, Dystrandept & $36^{\circ} 50^{\prime} \mathrm{S} ; 71^{\circ} 55^{\prime} \mathrm{W}$ \\
OSN & Medial, Mesic, Typic, Dystrandept & $40^{\circ} 32^{\prime} \mathrm{S} ; 73^{\circ} 05^{\prime} \mathrm{W}$ \\
DIG & Medial, Thermic, Typic, Dytrandept & $36^{\circ} 53^{\prime} \mathrm{S} ; 72^{\circ} 10^{\prime} \mathrm{W}$ \\
TCO & Medial, Mesic, Entic Dystrandep & $38^{\circ} 6^{\prime} \mathrm{S} ; 72^{\circ} 36^{\prime} \mathrm{W}$ \\
RAL & Mesic, Umbric, Vitrandept & $41^{\circ} 32^{\prime} \mathrm{S} ; 73^{\circ} 05^{\prime} \mathrm{W}$ \\
NBR & Ashy, Mesic, Hydric, Dystrandept & $41^{\circ} 19^{\prime} \mathrm{S} ; 73^{\circ} 06^{\prime} \mathrm{W}$ \\
FRU & Medial, Isomesic, Typic, Placandept & $41^{\circ} 06^{\prime} \mathrm{S} ; 73^{\circ} 07^{\prime} \mathrm{W}$ \\
\hline
\end{tabular}

Republished from [23] with permission from Elsevier Science \& Technology Journals. Permission conveyed through Copyright Clearance Center, Inc. COLL, Collipulli; MET, Metrenco; FRE, Freire; STB, Santa Bárbara; OSN, Osorno; DIG, Diguillín; TCO, Temuco; RAL, Ralún; NBR, Nueva Braunau; FRU, Frutillar.

\subsection{Analytical methods}

The quantitative analysis of 2,4-D was conducted by HPLC-DAD (Shimadzu, Kyoto, Japan) (Table 2). Quality parameters for the chromatographic analysis were previously established. Analytical sensitivity, detection, and quantification limits were $0.003,0.009$, and $0.032 \mu \mathrm{g} \mathrm{mL}^{-1}$, respectively (Table 2). These values were calculated from a calibration curve carried out at eight concentration levels: $0.025,0.050,0.075,0.100,0.250,0.500$, 0.750 , and $1.000 \mu \mathrm{g} \mathrm{mL}^{-1}$. The chromatographic response was found to be linear in this concentration range with an $R^{2}$ value of 0.999 . The data of 2,4-D in solutions were analyzed using SigmaPlot V13 (Systat Software, Inc., San Jose, CA, USA). The Surface-Enhanced Raman Scattering (SERS) measurements were performed using a Renishaw micro-Raman RM 1000 spectrometer, equipped with laser lines 514, 633, and $785 \mathrm{~nm}$. The spectrometer was coupled to a Leica microscope DMLM (Renishaw, Gloucestershire, UK), and a CCD camera electrically cooled. The Raman signal was calibrated to the $520 \mathrm{~cm}^{-1}$ line of silicon and lens of $50 \times$ objective. The laser power on the sample was about $0.2 \mathrm{~mW}$. Acquisition time was set between 10 and $20 \mathrm{~s}$ per accumulation; the average of accumulations was 5 with a spectral resolution of $4 \mathrm{~cm}^{-1}$. The spectra were recorded between 100 and $1800 \mathrm{~cm}^{-1}$. Spectral recording conditions and the laser line's choice to be used were selected to avoid degradation of the sample; in this sense, the 633 and $785 \mathrm{~nm}$ laser lines were used.

\subsection{Chemicals}

All reagents used were analytical or HPLC grade. All of these chemicals were used as received, and aqueous stock solutions of chemicals were made in ultrapure water (conductivity $0.05 \mu \mathrm{S} \mathrm{cm}^{-1}$ ). The analytical reference standard, 2,4-D (99.7\% purity; SigmaAldrich) was used for the preparation of the stock solution of $1 \mathrm{mg} \mathrm{mL}^{-1}$ in acetonitrile $(\mathrm{AcN})$ (Table 2). For the SERS measurements, the analyte's aqueous stock solutions were prepared in ultrapure water to a final concentration of $3.6 \times 10^{-3} \mathrm{M}$. A low charged Ag colloidal solution was used [28]. For colloidal solutions of silver nanoparticles (AgNps), we used silver nitrate 99.9999\% trace metals basis (product number 204390; Sigma-Aldrich, St. Louis, MO, USA), sodium hydroxide (product number 106469, EMSURE ${ }^{\circledR}$ ACS, Reag. Ph Eur; Merck, Darmstadt, Germany), and hydroxylamine hydrochloride 99.999\% trace metals basis (product number 431362; Sigma-Aldrich, St. Louis, MO, USA). 
Table 2. Uses, properties, and analytical details for 2,4-D.

\begin{tabular}{|c|c|c|c|c|c|c|c|c|}
\hline $\begin{array}{l}\text { Pesticide } \\
\text { Name } \\
\text { (CAS RN) }\end{array}$ & $\begin{array}{l}\text { Molar Mass } \\
\left(\mathrm{g} \mathrm{mol}^{-1}\right)\end{array}$ & \multicolumn{3}{|c|}{$\begin{array}{l}\text { Use and APPR }{ }^{1} \\
\left(\mathrm{~g} \mathrm{ha}^{-1}\right)\end{array}$} & $p K_{a}^{2}$ & $K_{o w}{ }^{3}$ & $\begin{array}{c}S_{w}{ }^{4} \\
\left(\mathrm{mg} \mathrm{L}^{-1}\right)\end{array}$ & $\begin{array}{l}\mathrm{DT}_{50}{ }^{5} \\
\text { (days) }\end{array}$ \\
\hline $\begin{array}{l}2,4-\mathrm{D} \\
(94-75-7)\end{array}$ & 221.04 & \multicolumn{3}{|c|}{$\begin{array}{l}\text { Post-emergence herbicide and selective mode } \\
\text { of action. The APPR of 2,4-D is very low } \\
\text { (280-2300) for weed control in corn. }\end{array}$} & 2.97 & $\begin{array}{l}0.027 \text { in alkaline } \\
\text { condition, } 29.23 \text { in } \\
\text { acidic condition }\end{array}$ & $\begin{array}{c}300 \text { at } p H=1 \text { and }>20,000 \\
\text { at } p H=5\left(20^{\circ} \mathrm{C}\right)\end{array}$ & $10-24$ \\
\hline \multicolumn{9}{|c|}{ HPLC Analysis } \\
\hline \multicolumn{2}{|c|}{ HPLC mobile phase } & $\begin{array}{l}\text { Flow rate } \\
\left(\mathrm{mL} \min ^{-1}\right)\end{array}$ & $\begin{array}{c}\text { Injection } \\
\text { volume }(\mu \mathrm{L})\end{array}$ & $\begin{array}{l}\text { Wavelength } \\
\quad(\mathrm{nm})\end{array}$ & $\begin{array}{l}\text { Temp } \\
\left({ }^{\circ} \mathrm{C}\right)\end{array}$ & \multicolumn{2}{|c|}{ Column } & $\begin{array}{l}\text { Detection limit } \\
\quad\left(\mathrm{mg} \mathrm{L}^{-1}\right)\end{array}$ \\
\hline \multicolumn{2}{|c|}{$\begin{array}{c}65: 35(v / v)= \\
\text { AcN:water at } p H 2.8\end{array}$} & 1 & 25 & 224 & $35^{\circ} \mathrm{C}$ & \multicolumn{2}{|c|}{$\begin{array}{c}\text { MultiHigh 100 RP C18 } \\
(150 \mathrm{~mm} \times 4.6 \mathrm{~mm} \mathrm{ID}, 5 \mu \mathrm{m}) .\end{array}$} & 0.009 \\
\hline
\end{tabular}

${ }^{1} \mathrm{APPR}=$ application rate [29]; ${ }^{2} p K_{a}=$ dissociation constant; ${ }^{3} K_{o w}=$ octanol/water partition coefficient [29]; ${ }^{4} S_{w}=$ solubility in water [30];

${ }^{5} \mathrm{DT}_{50}=$ half-life time in soil [3].

\subsection{Sorption Kinetic Experiments, Sorption-Desorption Experiments and Models}

\subsubsection{Kinetic Sorption Experiments}

Kinetic experiments were carried out at $25 \pm 1{ }^{\circ} \mathrm{C}$. Duplicate samples of $2 \mathrm{~g}$ of airdried soils were mixed with a $10 \mathrm{~mL}$ aliquot of an aqueous solution of $5 \mu \mathrm{g} \mathrm{mL}{ }^{-1} 2,4-\mathrm{D}$ (in $0.01 \mathrm{M} \mathrm{CaCl}_{2}$ ) in $50 \mathrm{~mL}$ centrifuge tubes. The tubes were shaken "end over end" at the natural $p H$ of soils during 5, 15,30,45, 60,90,120, and $180 \mathrm{~min}$ and then centrifuged at $3250 \mathrm{rpm}$ for $20 \mathrm{~min}$. Each supernatant was filtered through a $0.22 \mu \mathrm{m}$ membrane pore-size Millipore filter. The concentration of 2,4-D in solutions was determined by HPLC-DAD (Table 2). Interferences from soils were discarded through the corresponding purity and matching tests. Table 3 shows the theoretical and empirical description of each sorption kinetics model.

\subsubsection{Sorption-Desorption Experiments}

All isotherm experiments were carried out at $25 \pm 1{ }^{\circ} \mathrm{C}$. Duplicate samples of $2 \mathrm{~g}$ airdried soils were mixed with a $10 \mathrm{~mL}$ aliquot of aqueous solutions of 2,4-D at 5, 10, 15, 20 and $25 \mu \mathrm{g} \mathrm{mL}^{-1}$ (in $0.01 \mathrm{M} \mathrm{CaCl}_{2}$ ) in $50 \mathrm{~mL}$ centrifuge tubes. The tubes were shaken end-overend at natural $\mathrm{pH}$ of soils for $24 \mathrm{~h}$ to ensure equilibrium and then centrifuged at $3200 \mathrm{rpm}$ for $20 \mathrm{~min}$. The supernatant was filtered through a $0.22 \mu \mathrm{m}$ pore-size Millipore filter. Desorption was performed using the samples treated at $25 \mu \mathrm{g} \mathrm{mL} \mathrm{m}^{-1}$. After the sorption equilibrium was reached, $5 \mathrm{~mL}$ of the supernatant solution was replaced with $5 \mathrm{~mL}$ of herbicide-free $0.01 \mathrm{M} \mathrm{CaCl}_{2}$ solution, and samples were shaken again for $2 \mathrm{~h}$, followed by centrifugation. The same step was repeated four consecutive times; every time, an aliquot of the centrifuged supernatant was removed for analysis. The final concentration of 2,4-D in solution was determined by HPLC-DAD with the same analytical methods indicated previously in kinetics studies (Table 2). The amount of 2,4-D adsorbed was calculated from Equation (1) (Table 3). Table 3 shows the theoretical and empirical description of each sorption model.

\subsection{Sample preparation for the Raman and SERS Measurements}

Raman measurements were performed for the 2,4-D crystals deposited on a quartz slide. To evaluate the Andisol soil (NBR) interaction with 2,4-D, the following methodology was used: $0.0087 \mathrm{~g}$ of soil was added to $500 \mu \mathrm{L}$ of ultrapure water, and $10 \mu \mathrm{L}$ of $3.6 \times 10^{-3} \mathrm{M}$ aqueous solution of 2,4-D was added. The final concentration of 2,4-D in the sample was close to $7.0 \times 10^{-5} \mathrm{M}$. The above mixture was stirred for $20 \mathrm{~min}$ and allowed to stand for $24 \mathrm{~h}$ at room temperature, and then $500 \mu \mathrm{L}$ of silver colloid was added and stirred for $20 \mathrm{~min}$. Finally, the sample was centrifuged at $4000 \mathrm{rpm}$, the supernatant was removed, and then $5 \mu \mathrm{L}$ of the soil-AgNps sample was taken with a micropipette, and the SERS spectrum was recorded [31]. 
Table 3. Models used to describe sorption kinetic and sorption-desorption of 2,4-D on volcanic ash-derived soils ${ }^{1}$.

\begin{tabular}{|c|c|c|c|}
\hline Equation & Equation Number & Parameters & Theoretical and Empirical Description \\
\hline $\begin{array}{l}\text { Adsorbed quantity: } \\
q_{t}=\left(C_{0}-C_{\mathcal{e}}\right) \times V / M\end{array}$ & (1) & $\begin{array}{l}q_{t}: \text { Adsorbed quantity }\left(\mu \mathrm{g} \mathrm{g}^{-1}\right) \text { at any soil-solution contact time } t(\mathrm{~min}) \text { for } \\
\text { kinetic sorption experiments; } C_{0}: \text { Initial concentration of } 2,4-\mathrm{D} \text { in solution; } C_{e} \text { : } \\
\text { Equilibrium concentration of } 2,4-\mathrm{D} \text { in solution; } V / M \text { : Solution } / \text { soil ratio. }\end{array}$ & $\begin{array}{l}\text { The adsorbed quantity is obtained from a mass balance between initial } \\
\text { and equilibrium concentration of } 2,4-\mathrm{D} \text { in solution. This equation is valid } \\
\text { when degradation and precipitation are negligible during the sorption } \\
\text { process. }\end{array}$ \\
\hline \multicolumn{4}{|c|}{ Sorption kinetic models } \\
\hline $\begin{array}{l}\text { Pseudo-first-order (PFO) model [32]: } \\
\log \left(q_{\max }-q_{t}\right)=\log q_{\max }-\frac{k_{1}}{2.303} t\end{array}$ & (2) & $\begin{array}{l}q_{\max }: \text { is the maximum sorbed amount }\left(\mu \mathrm{g} \mathrm{g}^{-1}\right) \\
k_{1}: \text { Rate constant }\left(\min ^{-1}\right)\end{array}$ & $\begin{array}{l}\text { This equation fits better at high } C_{0} \text { values. The } k_{1} \text { is a combination of } \\
\text { sorption }\left(k_{a}\right) \text { and desorption }\left(k_{b}\right) \text { rate constants [33]. Its magnitude is } \\
\text { influenced by experimental conditions ( } p H \text { and temperature) and particle } \\
\left.\text { size (small particle size imply large values of } k_{1}\right) \text {. }\end{array}$ \\
\hline $\begin{array}{l}\text { Pseudo-second-order (PSO) } \\
\text { model [33-39]: } \\
\frac{t}{q_{t}}=\frac{1}{q_{\max }^{2} k_{2}}+\frac{1}{q_{\max }} t\end{array}$ & (3) & $\begin{array}{l}k_{2}: \text { Rate constant }\left(\mathrm{g} \mathrm{\mu g}^{-1} \min ^{-1}\right) . \\
\text { Derived parameters from Equation }(3): h \text { : Initial sorption rate }\left(\mathrm{g} \mathrm{gg}^{-1} \min ^{-1}\right) \text {, } \\
h=k_{2} q_{\max }{ }^{2} ; t_{1 / 2}: \text { Half-life time }(\min ), t_{1 / 2}=1 /\left(k_{2} q_{\max }\right) .\end{array}$ & $\begin{array}{l}\text { Better fits at low } C_{0} \text { values [33]. The } k_{2} \text { is a complex function of } C_{0} \text { with a } \\
\text { time scale factor that decreases when } C_{0} \text { increases. Additionally, this } \\
\text { model assumes sorption capacity to be proportional to the number of } \\
\text { active sites occupied on the soil [40]. }\end{array}$ \\
\hline \multicolumn{4}{|c|}{ Solute transport mechanism } \\
\hline $\begin{array}{l}q_{t}=\left(\frac{1}{\beta}\right) \ln (\alpha \beta)+\left(\frac{1}{\beta}\right) \ln (t) \\
\text { Dimensionless Elovich model [42]: } \\
\frac{q_{t}}{q_{\text {ref }}}=R_{E} \ln \left(\frac{t}{t_{\text {ref }}}\right)+1\end{array}$ & (5) & $\begin{array}{l}\alpha: \text { Initial sorption rate }\left(\mu \mathrm{g} \mathrm{g}^{-1} \mathrm{~min}^{-1}\right) ; \beta: \text { Number of sites available for the } \\
\text { sorption }(\mathrm{g} \mu \mathrm{g}-1) \text {, related to the extent of surface coverage and activation } \\
\text { energy for chemisorption; } R_{E}=1 /\left(q_{r e f} \beta\right): \text { Approaching equilibrium factor. } \\
\text { When } R_{E}>0.3 \text {, the curve rises slowly (Zone I), in the range } 0.3>R_{E}>0.1 \text {, the } \\
\text { curve rises moderately (Zone II); in the range } 0.1>R_{E}>0.02 \text {, the curve rises } \\
\text { rapidly (Zone III); and when } R_{E}<0.02 \text {, the curve reaches equilibrium instantly } \\
\text { (Zone IV). } t_{r e f}: \text { Longest time in the sorption process }\left(t_{r e f}=t \text { at equilibrium); }\right. \\
q_{r e f} \text { : Solid-phase concentration at } t=t_{r e f}\left(q_{r e f}=q_{\max }\right) ;(1 / \beta) \text { : rate constant } \\
\text { during the slow phase of the reaction. }\end{array}$ & $\begin{array}{l}\text { Describe second order kinetics only for systems with a heterogeneous } \\
\text { adsorbing surface. The deviations of the Elovich model at high surface } \\
\text { coverage could result in this model neglecting simultaneously occurring } \\
\text { desorption. At low surface coverage, this equation might be applied only } \\
\text { in cases of strongly heterogeneous surfaces. }\end{array}$ \\
\hline $\begin{array}{l}\text { Intraparticle Diffusion (IPD) } \\
\text { model [34,36]: } \\
q_{t}=k_{i n t} t^{1 / 2}+C \\
\text { Dimensionless Intraparticle Diffusion } \\
\text { (DIPD) model [43]: } \\
\frac{q_{t}}{q_{\text {ref }}}=1-R_{i}\left[1-\left(\frac{t}{t_{\text {ref }}}\right)^{\frac{1}{2}}\right]\end{array}$ & (7) & $\begin{array}{l}k_{\text {int } i}: \text { Rate constant of step } i\left(\mu \mathrm{g} \mathrm{g}^{-1} \mathrm{~min}^{1 / 2}\right) ; C_{i} \text { : Thickness of the boundary } \\
\text { layer in step } i\left(\mu \mathrm{g} \mathrm{g}^{-1}\right) ; R_{i}: \text { Initial sorption factor in step } i \text { (if } q_{r e f}=q_{e} \text {, the } \\
\text { applicability of dimensionless IPD model is limited to only one step). The initial } \\
\left.\left.\text { sorption can be weak (zone I, } 1>R_{i}>0.9\right) \text {, medium (zone II, } 0.9>R_{i}>0.5\right) \text {, } \\
\left.\text { strong (zone III, } 0.5>R_{i}>0.1\right) \text { or complete (zone IV, } R_{i}<0.1 \text { ) regarding the } \\
\text { equilibrium sorption. }\end{array}$ & $\begin{array}{l}C \text { is proportional to the boundary layer thickness representing the initial } \\
\text { sorption on external sites [44]. When } C_{1}=0 \text {, IPD is the most critical rate } \\
\text { process controlling sorption; } C_{1}>0, \text { IPD is not the only rate-controlling } \\
\text { step. Thus, the first step must be attributed to the EMT across the } \\
\text { boundary layer controlled by liquid film diffusion. The positive } \\
\text { intercepts result from the greater boundary layer effect indicating rapid } \\
\text { sorption on adsorbents with a wide distribution of pore sizes [43]. }\end{array}$ \\
\hline $\begin{array}{l}\text { Boyd model: } \\
\ln \left(1-\frac{q_{t}}{\eta_{e}}\right)=-0.4977-B t \\
B t=C+k \times t\end{array}$ & $\begin{array}{l}(8) \\
(9) \\
\end{array}$ & $\begin{array}{l}B=-D_{2} \pi^{2} / r^{2} \text { : Empirical constant related with the effective diffusion } \\
\text { coefficient }\left(\mathrm{D}_{2}\right) \text { and the effective particle size }\left(r^{2}\right) \text { for the sorption process. }\end{array}$ & $\begin{array}{l}\text { If the plot of Equation (9) is linear with } C=0 \text {, the rate of mass transfer is } \\
\text { controlled by pore diffusion. If the plot is non-linear or linear but } C \neq 0 \text {, } \\
\text { the film diffusion or chemisorption controls the sorption rate [32]. }\end{array}$ \\
\hline $\begin{array}{l}\text { Two-Site Non-Equilibrium (TSNE) } \\
\text { model [45]: } \\
\frac{C_{t}}{C_{i n}}= \\
\frac{1}{R}+\left(\frac{1}{\beta R}-\frac{1}{R}\right) \exp \left[-\left(\frac{k_{d e s}}{\beta}\right) t\right]\end{array}$ & (10) & 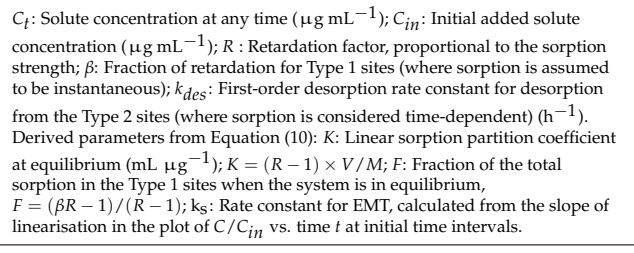 & $\begin{array}{l}\text { The sorption parameters } k_{d e s} \text { and } K \text { are inversely related for neutral } \\
\text { organic chemicals in soils and sediments [45]. The } k_{d e s} \text { is considered as a } \\
\text { parameter that indiscriminately combines several processes, such as } \\
\text { intra-OM diffusion and delayed IPD that control MT of sorbate into the } \\
O M \text { complex. }\end{array}$ \\
\hline \multicolumn{4}{|c|}{ Sorption-desorption process } \\
\hline $\begin{array}{l}\text { Sorbed and desorbed fraction: } \\
\% \text { fast ads }=100 \times\left(C_{1} / q_{e}\right) \\
\% \text { slow ads }=100-\% \text { fast ads }\end{array}$ & $\begin{array}{l}(11) \\
(12)\end{array}$ & $\begin{array}{l}\text { \%ads: Sorbed fraction (\%); \%des: Desorbed fraction (\%); } q_{e ~ a d s} \text { and } q_{e} \text { des }: 2,4-\mathrm{D} \\
\text { adsorbed in equilibrium }\left(\mathrm{\mu g} \mathrm{g}^{-1}\right) \text { for sorption and desorption batch } \\
\text { experiments, respectively. }\end{array}$ & $\begin{array}{l}\text { The sorbed fraction can be calculated by means of the IPD model if } \\
\text { different steps are present during the sorption process. }\end{array}$ \\
\hline $\begin{array}{l}\text { Linear model: } \\
q_{e}=K_{d} \times C_{e}\end{array}$ & (13) & $\begin{array}{l}K_{d}: \text { Linear soil-solution distribution coefficient. } \\
\text { Derived parameters from Equation (13): } K_{o c}\left(\text { from } K_{d}\right)=100 \times K_{d} / \% O C \text { : OC } \\
\text { distribution coefficient from } K_{d} \text {. }\end{array}$ & $\begin{array}{l}\text { The linear model is useful to describe sorption when the process is } \\
\text { independent of the solute concentration. }\end{array}$ \\
\hline $\begin{array}{l}q_{e \text { ads }}=K_{f a d s} \times C_{e(a d s)}{ }^{1 / n_{f a d s}} \\
\text { Freundlich model for desorption: } \\
q_{e \text { des }}=K_{f d e s} \times C_{e(d e s)}^{1 / n_{f d e s}}\end{array}$ & (14) & $\begin{array}{l}K_{f}: \text { Freundlich constant; } 1 / n \text { : Freundlich sorption coefficient. } \\
\text { Derived parameters from Equation (14): } \\
K_{f o c}: \text { OC distribution coefficient from } K_{f a d s} ; K_{f o c}=100 \times K_{f a d s} / \% O C \text {; } \\
H: \text { Hysteresis coefficient for sorption loop; } H=\left(1 / n_{\text {des }}\right) /\left(1 / n_{\text {ads }}\right) .\end{array}$ & $\begin{array}{l}\text { The Freundlich model assumes a heterogeneous surface [46]. The single } \\
K_{f} \text { term implies that the energy of sorption on a homogeneous surface is } \\
\text { independent of surface coverage [47]. In this sense, the energy of binding } \\
\text { is the same for the adsorptive sites, and interactions between adsorbed } \\
\text { atoms do not exist [46]. } \\
\text { The } n \text { coefficient is related to the surface heterogeneity and the diversity } \\
\text { of the energies associates with the sorption reaction [48]. If } 1 / n>1, \text { the } \\
\text { sorption process shows cooperative sortion; If } 1 / n=1 \text {, Freundlich } \\
\text { model is equivalent to Linear model indicating low heterogeneity among } \\
\text { the sites of the sorbent [48]; If } 1 / n<1 \text {, the relative sorption decreases } \\
\text { when the concentration increases. This is characteristic of an L-type } \\
\text { sorption isotherm and suggests that specific sites approached saturation } \\
\text { as herbicide concentration increased [5], indicating that the sorption } \\
\text { firstly occurred on higher energy sites of sorption, followed by low } \\
\text { energy sites [49]. } \\
\text { A value of } H \text { close to } 1 \text { means that hysteresis is absent, while a value of } \\
H<1 \text { indicates that hysteresis takes place. }\end{array}$ \\
\hline
\end{tabular}

Republished from [23] with permission from Elsevier Science \& Technology Journals. Permission conveyed through Copyright Clearance Center, Inc. ${ }^{1}$ Goodness-of-fit (higher values of determination coefficients $\left(R^{2}\right)$, lower standard error $(S E)$ for each parameter), the relationship between the theoretical basis for each kinetic sorption model was used as criteria to define the most suitable model to describe 2,4-D sorption kinetics 2,4-D transport mechanisms on VADS. Complementary, the accuracy to predict $q_{\max }$ (from pseudo-first-order (PFO) and pseudo-second-order (PSO) models) and $K_{d}$ (from Two-Site Non-Equilibrium (TSNE) model) were used.

\subsection{Statistical Analysis}

Pearson's correlation matrix was used to identify the most correlated variables between VADS properties and 2,4-D sorption coefficient. The "psych" and "corrplot" $R$ packages were employed to perform the correlation analysis, correlogram as well as to assess the potential of multiple linear regression (MLR) models as exploratory modeling. The study was started with 40 soil descriptors or pairwise soil interactions selected to represent different sources of physiochemical information of the VADS regarding their 
properties like texture, charge, soil constituents, and $p H$ (Table 4). The inter-descriptor correlation coefficient used was less than $R^{2}<0.6$ to avoid descriptors being intercorrelated. The generated dataset was used in an automated soil descriptors selection procedure using the best subset and stepwise model selection procedures. These methods were used to reduce data dimensionality and determine if a complex model (more soil descriptors) was significantly better than a less complex model. In this regard, $K_{f}$ values for each soil were modeled using VADS properties individually, and the pairwise products of texture soil properties and soil constituents (e.g., Sand $\times$ Clay or $F e_{P y r o} \times F e_{D C B}$ ) to begin to account for interactions between these variables. Additionally, texture soil properties normalized by OC content were included.

Table 4. Main physicochemical properties and mineral composition of volcanic ash-derived soils used in this study.

\begin{tabular}{|c|c|c|c|c|c|c|c|c|c|c|}
\hline Soils & COLL & MET & FRE & STB & OSN & DIG & TCO & RAL & NBR & FRU \\
\hline \multicolumn{11}{|c|}{ Physicochemical Properties } \\
\hline$O C(\%)$ & 1.5 & 2.3 & 4.5 & 5.1 & 5.1 & 5.8 & 6.4 & 6.9 & 9.5 & 11.0 \\
\hline$p \mathrm{H}_{\mathrm{H}_{2} \mathrm{O}(1: 2.5)}$ & 5.2 & 4.7 & 4.4 & 5.7 & 4.6 & 6.2 & 5.4 & 4.4 & 4.1 & 4.1 \\
\hline$C E C$ & 8.7 & 9.3 & 7.1 & 10.3 & 9.8 & 11.8 & 12.1 & 7.1 & 10.3 & 9.5 \\
\hline Sand $(\%)$ & 13.7 & 8.0 & 21.3 & 7.2 & 10.1 & 35.5 & 16.1 & 47.3 & 6.2 & 16.3 \\
\hline Silt $(\%)$ & 40.7 & 56.7 & 54.2 & 66.5 & 50.9 & 45.1 & 58.2 & 38.5 & 66.2 & 63.9 \\
\hline Clay (\%) & 45.7 & 35.3 & 24.5 & 26.3 & 39.1 & 19.4 & 25.7 & 12.9 & 27.6 & 19.7 \\
\hline$F e_{P Y R O}(\%)$ & 0.7 & 0.8 & 2.2 & 0.3 & 1.4 & 0.4 & 0.7 & 1.8 & 1.8 & 1.0 \\
\hline$F e_{O X}(\%)$ & 0.9 & 1.8 & 2.5 & 1.9 & 2.0 & 1.9 & 2.2 & 1.4 & 3.3 & 0.6 \\
\hline$F e_{D C B}(\%)$ & 6.2 & 7.1 & 4.3 & 5.3 & 3.0 & 3.5 & 3.9 & 1.4 & 5.1 & 0.6 \\
\hline IEP & 2.0 & 2.5 & 3.1 & 3.8 & 2.1 & 2.6 & 2.9 & 3.3 & 3.3 & 2.9 \\
\hline \multicolumn{11}{|l|}{ Mineral } \\
\hline Allophane & & & +++++ & +++++ & +++++ & +++++ & +++++ & +++++ & +++++ & +++++ \\
\hline$\alpha$-Cristobalite & + & & + & & + & & ++ & + & + & + \\
\hline Chlorite-AL & & & & + & & & & ++ & & \\
\hline Feldspars & & & & & + & & + & & + & \\
\hline Ferrihydrite & & & + & & & + & + & & + & \\
\hline Gibbsite & & & ++ & + & & & ++ & & ++ & \\
\hline Goethite & & + & & & & & & & & \\
\hline Halloysite & + & +++++ & & ++ & +++ & ++ & & & & + \\
\hline Kaolinite & +++++ & & & & & & & & & \\
\hline Montmorillonite & & & & & & & & + & & \\
\hline Organo-allophanic & & & ++ & + & ++ & + & ++ & & ++ & + \\
\hline Plagioclase & & & & & + & ++ & & ++ & & + \\
\hline Quartz & & + & + & & & & & & & \\
\hline Vermiculite & + & & & ++ & + & + & & & & ++ \\
\hline
\end{tabular}

Republished from [23] with permission from Elsevier Science \& Technology Journals. Permission conveyed through Copyright Clearance Center, Inc. $\mathrm{Fe}_{\mathrm{PYRO}}, \mathrm{Fe}_{\mathrm{OX}}$, and $\mathrm{Fe}_{\mathrm{DCB}}$ represent $\mathrm{Fe}$ oxides extracted by pyrophosphate, acid ammonium oxalate, and dithionite citrate bicarbonate solutions, respectively. +++++ Represents dominant $(>50 \%),+++$ represents common $(5-20 \%),++$ represents present $(1-5 \%)$, and + represents trace fraction $(<1 \%)$.

The pairwise interactions chosen in the MLR analysis were based on the previously presented antecedents of physical properties (e.g., $p H$ and texture interactions moderate the surface charge of the minerals but may also impact the net charge of the 2,4-D molecule).

$$
K_{f}=c+\sum_{i=1}^{n} s_{i} S_{i}+p_{i} P_{i}
$$

In Equation (16), $s_{i}$ and $p_{i}$ are coefficients related to the properties of VADS individually and pairwise, respectively. Models were compared through various statistical tests; a high F-statistic value was used combined with the $p$-value $<0.05$ to assess the regression model's significance. $R_{a d j}^{2}$ was used as a measure of the goodness of fit. 


\section{Results and Discussion}

\subsection{Physiochemical Properties of VADS}

The soils studied presented acidic $p H$ (4.1-5.7, Table 4). 2,4-D is a phenoxyacetic acid with ionic equilibrium constants related to the acidic carboxyl group $\left(p K_{a}=2.97\right.$, Table 2). 2,4-D is in the anionic form according to its $p K_{a}$ values (Table 2) and may be relatively mobile in aqueous systems. All soils presented a negative net charge (IEP value lower than its $\mathrm{pH}_{\mathrm{H}_{2} \mathrm{O}}$ ) (Table 4). Ultisol soils presented the lowest OC content and IEP than Andisols and a higher clay mineral per cent (Table 4).

\subsection{Sorption Kinetics}

The amount of 2,4-D adsorbed per unit mass of the adsorbent increased quickly during the first $10 \mathrm{~min}$ in all VADS, followed by slower progress toward equilibrium (Figure 1a).

\section{Pseudo-First-Order (PFO) and Pseudo-Second-Order (PSO) Models}

Table 3 shows the theoretical and empirical descriptions for each sorption kinetic model. The PSO model correctly described 2,4-D sorption data at all-time intervals $\left(R^{2}>0.9992 ;\right.$ Table S1, Figure S1a). The $q_{\max }$ values estimated by PSO model agreed with the experimental data and yielded suitable $S E$ for $q_{\max }$ and $k_{2}$ values (Table 5, Figure $1 \mathrm{~b}$ ). 2,4-D showed the slowest sorption on RAL and NBR soils (highest OC content; Table 4) and DIG soil (intermediate OC content; Table 4). For Ultisols, the differences were more pronounced in the early stages of 2,4-D sorption, where the lowest $h$ and highest $t_{1 / 2}$ values were observed in Ultisols and DIG soil (Table 5). A higher $q_{\max }$ of 2,4-D was observed in NBR soil (highest $O C$ and silt content, Table 4). For Andisols, $O C$ content showed a positive correlation with $q_{\max }$ (Table S2). In general, the sorption kinetic process depends on adsorbate properties (size and functional groups), adsorbent texture (pore size), and surface heterogeneity (surface chemistry) [38,50,51]. The degree of heterogeneity has been related to textural properties (porous features) and chemical factors of the sorbent (composition), which may have different implications in the overall sorption process [38], where the higher $k_{2}$ values were observed in small-sized adsorbates by reduction of the MT effects.

Table 5. Kinetic parameters predicted from linear analysis of pseudo-second-order model.

\begin{tabular}{|c|c|c|c|c|c|c|c|c|c|c|}
\hline Parameters & COLL & MET & FRE & STB & OSN & DIG & TCO & RAL & NBR & FRU \\
\hline$q_{\max }(\exp )$. & 9.0 & 9.5 & 12.0 & 15.7 & 13.5 & 8.1 & 13.2 & 24.5 & 38.9 & 14.9 \\
\hline \multicolumn{11}{|c|}{ Pseudo-second order } \\
\hline$q_{\max }\left(\mu g g^{-1}\right)^{a}$ & 9.3 & 8.9 & 12.1 & 15.8 & 14.0 & 9.9 & 13.5 & 24.9 & 39.7 & 14.9 \\
\hline$k_{2}\left(g_{\mu g}^{-1} \min ^{-1}\right)^{a}$ & $1 \times 10^{-2}$ & $2 \times 10^{-2}$ & $2 \times 10^{-2}$ & $2 \times 10^{-2}$ & $1 \times 10^{-2}$ & $9 \times 10^{-3}$ & $1 \times 10^{-2}$ & $9 \times 10^{-3}$ & $8 \times 10^{-3}$ & $5 \times 10^{-2}$ \\
\hline$R^{2}$ & 0.9992 & 0.9993 & 0.9997 & 0.9997 & 0.9992 & 0.9997 & 0.9996 & 0.9992 & 0.9999 & 1.0000 \\
\hline$h\left(\mathrm{~g} \mu \mathrm{g}^{-1} \min ^{-1}\right)^{\mathrm{a}}$ & 1.2 & 1.4 & 3.6 & 5.8 & 2.4 & 0.9 & 2.6 & 5.6 & 13.3 & 11.6 \\
\hline$t_{1 / 2}(\min )^{a}$ & 7.7 & 6.4 & 3.3 & 2.7 & 5.7 & 11.5 & 5.1 & 4.5 & 3.0 & 1.3 \\
\hline
\end{tabular}

a $\mid$ Standard error $\mid \leq 0.1$ in all the parameters.

\subsection{Solute Transport Mechanism}

\subsubsection{Elovich Model}

The RAL, MET, and COLL soils presented the highest $R^{2}$ values $(0.9890,0.9794$, and 0.9724, respectively; Figure 1c, Table 6). Moreover, the low OC content confers active sites with some characteristics of an energetically heterogeneous surface [22]. The FRU and FRE soils presented the highest values for $\alpha$ and $\beta$ (Table 6), with a high number of sites available for 2,4-D sorption in the initial phase [34]. The linear plot of $q t$ versus $\ln t$ in the Elovich linear equation for each soil is shown in Figure 1c. The highest intercept $((1 / \beta) \ln (\alpha \beta))$ and slope $(1 / \beta)$ were observed in NBR followed by TCO and FRU, indicating the highest amount adsorbed of 2,4-D during the initial fast phase and rate constant during the slow phase of 2,4-D sorption on these soils, respectively. Nonlinear data analysis results (Figure S1b, Table S1) showed a good adjustment for MET and OSN soils $\left(R^{2}=0.9525\right.$ and $R^{2}=0.9157$, respectively) lying in zone III $\left(0.1>R_{E}>0.02\right.$; the curve rises rapidly) (Figure S1b and Table S1). 


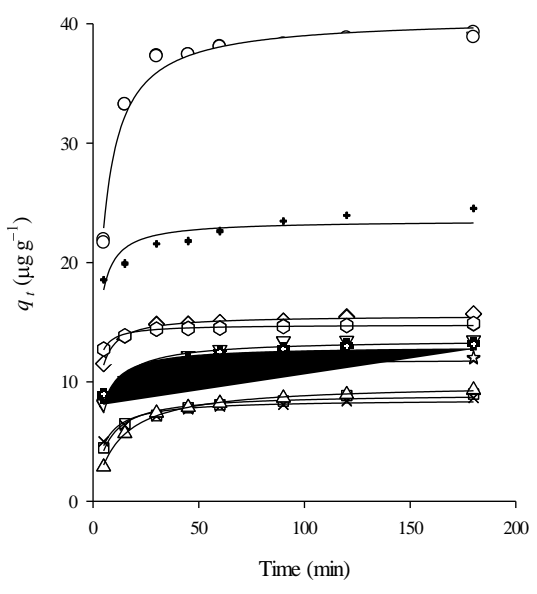

(a)

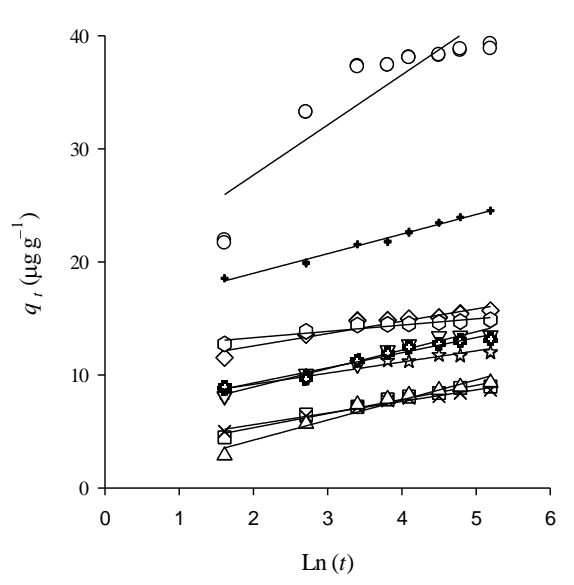

(c)

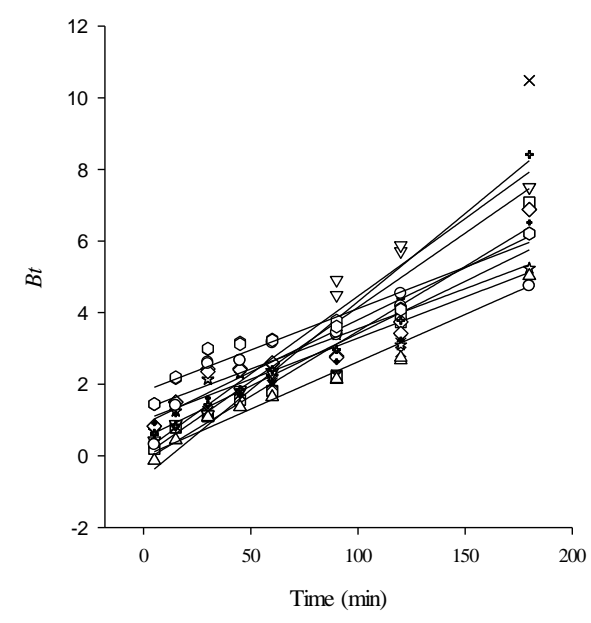

(e)

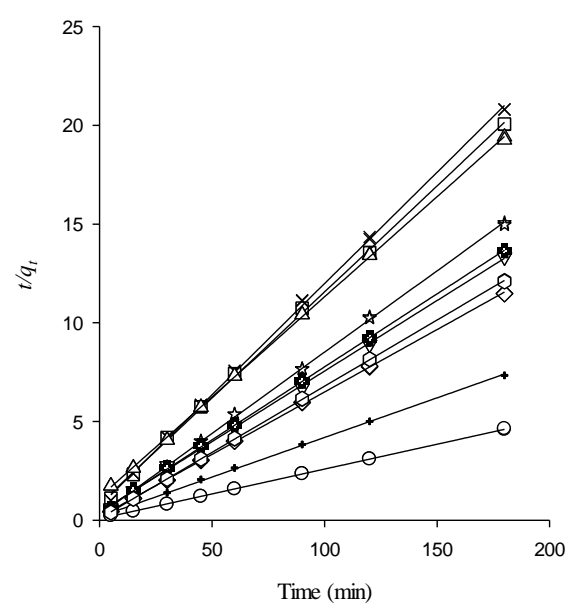

(b)

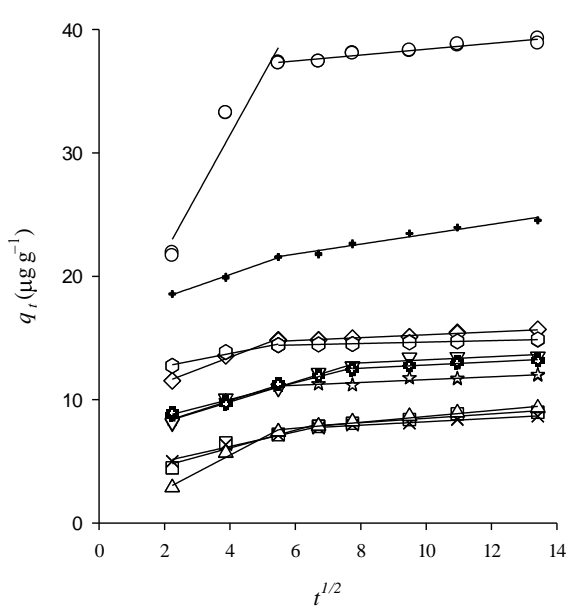

(d)

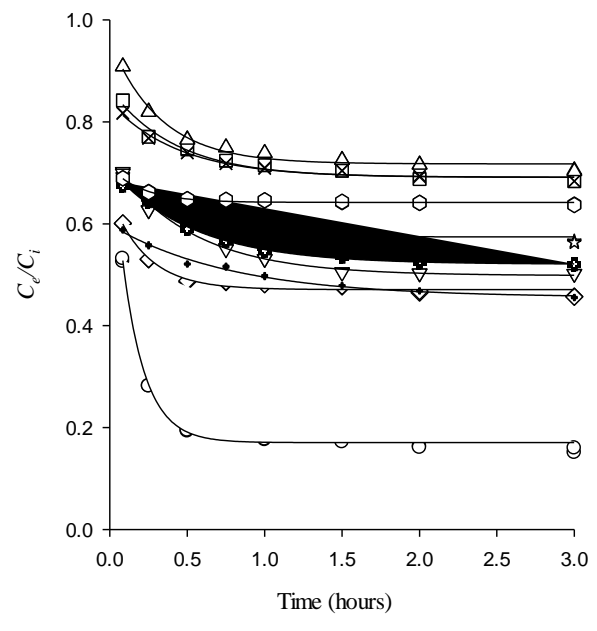

(f)

Figure 1. Plot for 2,4-D sorption on volcanic ash-derived soils: COLL ( $\square)$, MET ( $\times$ ), FRE (ઐ), STB ( $\diamond), \operatorname{OSN}(\nabla), \operatorname{DIG}(\triangle)$, TEM (+), RAL (+), NBR ( $\bigcirc$ ) and FRU (@). (a) Hyperbolic; (b) Pseudo-second-order (PSO); (c) Elovich; (d) Intraparticle Diffusion (IPD); (e) Boyd, and (f) Two-Site Non-Equilibrium (TSNE) models. Symbols represent the experimental data, and lines represent the theoretical curves described by each model. 
Table 6. Kinetic parameters predicted from the linear analysis of Elovich, Intraparticle Diffusion (IPD), and Boyd models and non-linear analysis for Two-Site Non-Equilibrium model (TSNE).

\begin{tabular}{|c|c|c|c|c|c|c|c|c|c|c|}
\hline Parameters & COLL & MET & FRE & STB & OSN & DIG & TCO & RAL & NBR & FRU \\
\hline$K_{d}$ (exp.) & 2.4 & 2.9 & 4.3 & 6.9 & 5.4 & 2.3 & 5.1 & 10.8 & 50.4 & 4.7 \\
\hline \multicolumn{11}{|c|}{ Elovich } \\
\hline$\alpha\left(\mu g^{-1} \min ^{-1}\right)$ & $12.0 \pm 0.2^{\mathrm{a}}$ & $32.5 \pm 0.2$ & $(1.0 \pm 0.3) 10^{3}$ & $(2.0 \pm 0.4) 10^{4}$ & $52.8 \pm 0.3$ & $2.6 \pm 0.4$ & $(2.0 \pm 0.0) 10^{2}$ & $(1.0 \pm 0.1) 10^{4}$ & $(3.0 \pm 2.3) 10^{2}$ & $(2.0 \pm 0.2) 10^{9}$ \\
\hline$\beta\left(\mathrm{g} \mu \mathrm{g}^{-1}\right)$ & $0.8 \pm 0.1$ & $1.0 \pm 0.1$ & $1.0 \pm 0.1$ & $0.9 \pm 0.1$ & $0.6 \pm 0.1$ & $0.6 \pm 0.1$ & $0.7 \pm 0.0$ & $0.6 \pm 0.1$ & $0.2 \pm 0.6$ & $1.8 \pm 0.1$ \\
\hline$R^{2}$ & 0.9724 & 0.9794 & 0.9239 & 0.9016 & 0.9652 & 0.9505 & 0.9652 & 0.9890 & 0.7961 & 0.8956 \\
\hline \multicolumn{11}{|c|}{ Intraparticle Diffusion } \\
\hline$k_{\text {int } 1}\left(\mu \mathrm{gg}^{-1}\right)$ & $0.7 \pm 0.0$ & $0.6 \pm 0.0$ & $0.8 \pm 0.0$ & $1.0 \pm 0.0$ & $0.8 \pm 0.0$ & $1.4 \pm 0.1$ & $0.7 \pm 0.0$ & $1.0 \pm 0.0$ & $4.8 \pm 0.6$ & $0.5 \pm 0.0$ \\
\hline$c_{1}\left(\mu g^{-1}\right)$ & $3.2 \pm 0.4$ & $3.8 \pm 0.3$ & $6.5 \pm 0.2$ & $9.4 \pm 0.3$ & $6.6 \pm 0.2$ & $0.0 \pm 0.4$ & $7.3 \pm 0.2$ & $16.4 \pm 0.1$ & $12.3 \pm 2.3$ & $11.7 \pm 0.2$ \\
\hline$R^{2}$ & 0.9360 & 0.9796 & 0.9968 & 0.9828 & 0.9780 & 0.9824 & 0.9862 & 0.9954 & 0.9323 & 0.9675 \\
\hline$k_{\text {int } 2}\left(\mu \mathrm{gg}^{-1}\right)$ & $0.2 \pm 0.0$ & $0.1 \pm 0.0$ & $0.1 \pm 0.0$ & $0.1 \pm 0.0$ & $0.1 \pm 0.0$ & $0.2 \pm 0.0$ & $0.1 \pm 0.0$ & $0.4 \pm 0.0$ & $0.2 \pm 0.0$ & $0.1 \pm 0.0$ \\
\hline$C_{2}\left(\mu \mathrm{gg}^{-1}\right)$ & $6.7 \pm 0.1$ & $6.8 \pm 0.1$ & $10.5 \pm 0.1$ & $14.1 \pm 0.0$ & $12.0 \pm 0.4$ & $6.2 \pm 0.1$ & $11.5 \pm 0.2$ & $19.4 \pm 0.2$ & $36.4 \pm 0.1$ & $14.1 \pm 0.0$ \\
\hline$R^{2}$ & 0.9400 & 0.9788 & 0.8878 & 0.9553 & 0.6203 & 0.9649 & 0.9254 & 0.9630 & 0.9324 & 0.9905 \\
\hline \multicolumn{11}{|c|}{ Boyd } \\
\hline C & $-0.2 \pm 0.2$ & $-0.6 \pm 0.5$ & $1.0 \pm 0.1$ & $1.0 \pm 0.2$ & $0.1 \pm 0.2$ & $0.0 \pm 0.1$ & $-0.0 \pm 0.2$ & $0.5 \pm 0.2$ & $1.3 \pm 0.2$ & $1.8 \pm 0.1$ \\
\hline$k\left(\min ^{-1}\right)$ & $0.04 \pm 0.00$ & $0.05 \pm 0.00$ & $0.02 \pm 0.00$ & $0.03 \pm 0.00$ & $0.04 \pm 0.00$ & $0.03 \pm 0.00$ & $0.04 \pm 0.00$ & $0.03 \pm 0.00$ & $0.02 \pm 0.00$ & $0.02 \pm 0.00$ \\
\hline$R^{2}$ & 0.9498 & 0.8102 & 0.9333 & 0.9005 & 0.9742 & 0.9699 & 0.9411 & 0.9278 & 0.8289 & 0.9366 \\
\hline \multicolumn{11}{|c|}{ Two Site Non-Equilibrium } \\
\hline$K\left(\mathrm{~mL} \mathrm{~g}^{-1}\right)$ & $2.2 \pm 0.0$ & $2.2 \pm 0.0$ & $3.7 \pm 0.0$ & $5.6 \pm 0.0$ & $5.0 \pm 0.0$ & $2.0 \pm 0.0$ & $4.6 \pm 0.0$ & $6.0 \pm 0.0$ & $24.3 \pm 0.2$ & $2.8 \pm 0.0$ \\
\hline$F$ & $0.4 \pm 0.0$ & $0.4 \pm 0.0$ & $0.5 \pm 0.0$ & $0.5 \pm 0.0$ & $0.4 \pm 0.0$ & $0.1 \pm 0.0$ & $0.5 \pm 0.0$ & $0.6 \pm 0.00$ & $0.1 \pm 0.0$ & $0.7 \pm 0.0$ \\
\hline$k_{\text {des }}\left(\mathrm{h}^{-1}\right)$ & $1.9 \pm 0.3$ & $1.9 \pm 0.2$ & $3.2 \pm 0.5$ & $3.2 \pm 0.5$ & $1.3 \pm 0.3$ & $2.3 \pm 0.0$ & $1.4 \pm 0.1$ & $1.0 \pm 0.1$ & $1.5 \pm 0.4$ & $4.2 \pm 0.5$ \\
\hline$R^{2}$ & 0.9712 & 0.9857 & 0.9713 & 0.9715 & 0.9887 & 0.9840 & 0.9948 & 0.9879 & 0.9939 & 0.9774 \\
\hline$k_{S}\left(\mathrm{~h}^{-1}\right)$ & $0.1 \pm 0.1$ & $0.1 \pm 0.0$ & $0.2 \pm 0.0$ & $0.3 \pm 0.0$ & $0.2 \pm 0.0$ & $0.3 \pm 0.0$ & $0.2 \pm 0.0$ & $0.1 \pm 0.0$ & $0.6 \pm 0.0$ & $0.1 \pm 0.0$ \\
\hline$R^{2}$ & 0.8269 & 0.8868 & 0.9691 & 0.9378 & 0.9257 & 0.9371 & 0.9518 & 0.9126 & 0.8597 & 0.9116 \\
\hline
\end{tabular}

a Standard error.

\subsubsection{Intraparticle Diffusion (IPD) Model}

The $\mathrm{q}_{\mathrm{t}}$ vs. $\mathrm{t}^{1 / 2}$ plots were multilinear in all soils (Figure $1 \mathrm{~d}$ ). 2,4-D sorption tends to be followed by two differentiated steps (Figure 1d) [44]. For all VADS, external MT (EMT) was the rate-controlling step at the initial period (45 $\mathrm{min}$ ) of 2,4-D sorption due to the high \% fast ads values (Table 6). For all VADS, the first linear section was far from the origin $\left(C_{1}>0.00 ; R^{2}>0.9323\right.$; Table 6$)$, except in DIG $\left(C_{1}=0.00\right.$ and highest \% slow ads value; Tables 6 and 7). A gradual 2,4-D sorption stage was accounted in the second linear section, where 2,4-D diffuses slowly through less accessible sites (smaller pores) on VADS until the equilibrium plateau is reached (Figure 1d; Table 6). Easy access to 2,4-D was observed in RAL where 2,4-D diffuses quickly within micropores (highest $k_{\text {int }} 2$, Table 6) due to the wide distribution of internal pore size. For all VADS, a positive correlation was observed between $O C$ and $C_{1}, \%$ fast ads and $k_{2} ; \%$ Type 1 sites and $k_{2}$; and \%Type 1 sites and $h$ (Table S2). These data placed these soils in the third zone (strong initial sorption, $0.5>R_{i}>0.1$ ) (Figure S1c, Table S1).

Table 7. Sorption/desorption of 2,4-D on volcanic ash-derived soils.

\begin{tabular}{|c|c|c|c|c|c|c|c|c|c|c|}
\hline Parameters & COLL & MET & FRE & STB & OSN & DIG & TCO & RAL & NBR & FRU \\
\hline$\%$ ads $(\%)$ & 53 & 56 & 52 & 54 & 54 & 56 & 70 & 59 & 69 & 71 \\
\hline$\%$ fast ads $(\%)$ & 34 & 43 & 54 & 60 & 47 & 8 & 54 & 55 & 31 & 79 \\
\hline$\%$ slow ads $(\%)$ & 66 & 57 & 47 & 41 & 53 & 92 & 46 & 45 & 69 & 22 \\
\hline \multicolumn{11}{|c|}{ Linear } \\
\hline$K_{d}\left(\mathrm{~mL} \mathrm{~g}^{-1}\right)$ & $2.4+0.0$ & $0.4+0.1$ & $4.0+0.2$ & $5.2+0.4$ & $5.3+0.1$ & $2.4+0.1$ & $7.8+0.3$ & $9.1+0.4$ & $48.8+1.5$ & $5.6+0.1$ \\
\hline$R^{2}$ & 0.9982 & 0.8777 & 0.9753 & 0.9653 & 0.9961 & 0.9908 & 0.9899 & 0.9886 & 0.9925 & 0.9964 \\
\hline$K_{o c}$ & 160 & 19 & 89 & 103 & 105 & 42 & 122 & 132 & 514 & 51 \\
\hline \multicolumn{11}{|c|}{ Freundlich } \\
\hline$K_{\text {fads }}\left(\mu \mathrm{g}^{1-1 / \mathrm{n}} \mathrm{mL}^{1 / \mathrm{n}} \mathrm{g}^{-1}\right)$ & $2.6+0.1$ & $16.2+0.2$ & $18.6+0.4$ & $23.4+0.7$ & $4.3+0.3$ & $10.6+0.3$ & $1.1+0.1$ & $24.1+0.6$ & $20.2+0.8$ & $5.3+0.4$ \\
\hline $1 / n_{\text {fads }}$ & $1.0+0.0$ & $0.2+0.0$ & $0.5+0.0$ & $0.5+0.0$ & $1.1+0.0$ & $0.6+0.0$ & $1.7+0.0$ & $0.7+0.0$ & $1.5+0.0$ & $1.0+0.0$ \\
\hline$R^{2}$ & 0.9981 & 0.9908 & 0.9981 & 0.9961 & 0.9971 & 0.9982 & 0.9983 & 0.9987 & 0.9983 & 0.9967 \\
\hline$K_{f o c}$ & 175 & 704 & 412 & 460 & 84 & 183 & 17 & 350 & 212 & 48 \\
\hline \multicolumn{11}{|c|}{ Desorption } \\
\hline$K_{f d e s}\left(\mu g^{1-1 / n} m^{1 / n} g^{-1}\right)$ & $17.3+0.2$ & $21.6+0.1$ & $33.4+0.4$ & $51.0+0.5$ & $19.1+0.6$ & $16.3+0.2$ & $23.3+0.4$ & $1.0+1.1$ & $104.4+1.5$ & $46.7+0.4$ \\
\hline $1 / n_{\text {fdes }}$ & $0.3+0.0$ & $0.1+0.0$ & $0.3+0.0$ & $0.2+0.0$ & $0.5+0.0$ & $0.4+0.0$ & $0.5+0.0$ & $0.4+0.0$ & $0.4+0.0$ & $0.2+0.0$ \\
\hline$R^{2}$ & 0.9983 & 0.9901 & 0.9971 & 0.9921 & 0.9933 & 0.9987 & 0.9975 & 0.9932 & 0.9923 & 0.9963 \\
\hline$\% \operatorname{des}(\%)$ & 86 & 92 & 80 & 83 & 75 & 83 & 74 & 72 & 41 & 85 \\
\hline \multicolumn{11}{|c|}{ Hysteresis } \\
\hline$H$ & 0.3 & 0.4 & 0.5 & 0.4 & 0.5 & 0.7 & 0.3 & 0.6 & 0.3 & 0.2 \\
\hline
\end{tabular}




\subsubsection{Boyd Model}

All plots were linear and passed through the origin, except for FRE, STB, RAL, NBR, and FRU (Figure 1e, Table 6). The film diffusion or chemisorption controls the overall sorption rate of 2,4-D in the last soils (homogenous adsorbents) [21,32,37].

\subsubsection{Two-Site Non-Equilibrium (TSNE) Model}

For all VADS, this model well described the 2,4-D sorption kinetics data $\left(R^{2}>0.8269\right.$; Figure 1f, Table 6). Concentration decay curves showed an initial step where the 2,4-D uptake was fast in FRU soil (highest $F$ and \% fast ads values; Figure 1f, Tables 6 and 7), followed by a second phase in which the uptake steadily increased up to equilibrium conditions. The high OC content in NBR soil increased the diffusion path length (highest $q_{\max }$, lowest $k_{2}$ and high \% slow ads values; Tables 5 and 6), resulting in an IOMD [24]. 2,4-D presented the highest $k_{\text {des }}$ values in FRE, STB, DIG, and FRU soils. The fast and slow desorption in soils has been attributed to soft carbon $\left(O C_{S}\right.$; humic/fulvic acids and lipids) and hard carbon $\left(\mathrm{OC}_{H}\right.$; black carbon), respectively (Table S4). Finally, for all VADS, a direct correlation was observed between $k_{\text {int } 1}$ and $k_{S}$ (Table S2).

The soils constituents such as $\mathrm{Al} / \mathrm{Fe}$ oxides, $S O M$, and mineral composition may influence the chemical non-equilibrium of 2,4-D on VADS. The soil texture plays a more critical role in the ionizable herbicide sorption than $O C$ content on sandy soils $[52,53]$, where $\mathrm{Al} / \mathrm{Fe}$ oxides promote aggregates. The resulting porosity will differentially impact the chemical associations and soils' physical properties [21,54] Other studies have indicated that ionizable herbicide sorption such as glyphosate in sandy loam soils is dominated by preferential flow mechanisms (physical non-equilibrium) [52,55].

An overview of the reported $k_{1}$ and $k_{2}$ values obtained in different experimental conditions (contact time, $p H$ and temperature) of 2,4-D on variable-charge soils (VChS), permanent-charge soils (PChS), and different minerals are given in Table S3. The sorbent varied considerably in composition (ranging from pure minerals to soils with different texture, OC content, and mineralogy. These studies showed that 2,4-D sorption kinetics in Andisols followed two-step sorption, and the sorption rate was $p H$-dependent (Table S3). The first stage accounts for a fast step where most of the sorption occurs, followed by a slower stage (DIP). It was found that chemisorption and external diffusion are the predominant 2,4-D sorption mechanisms.

\subsection{Sorption Models}

2,4-D sorption was studied over a wide range of concentrations $\left(5-25 \mu \mathrm{g} \mathrm{mL} \mathrm{L}^{-1}\right)$. Table 3 shows a theoretical and empirical description of each sorption model. For all soils, the Freundlich model described the 2,4-D sorption data with $R^{2} \geq 0.9908$ (Table 7). 2,4-D was adsorbed in all VADS with $K_{f}$ values between 1.1 and $24.1 \mu \mathrm{g}^{1-1 / \mathrm{n}} \mathrm{mL}^{1 / \mathrm{n}} \mathrm{g}^{-1}$ (Table 7). The highest 2,4-D $K_{f}$ values were observed in NBR, STB, and RAL soils due to their high $\mathrm{OC}$ content, $\mathrm{Fe} / \mathrm{Al}$ oxides, allophane, and positive surface charge (Table 4). $\mathrm{Fe} / \mathrm{Al}$ oxides, goethite, and gibbsite are also present in these VADS as extractable or free $\mathrm{Fe} / \mathrm{Al}$ oxides (Table 4) [56]. As both oxides present a IEP value $>7$ [57], the functional groups will be found as cationic species at the natural soil $p H$ and would favor the ionic interaction with anionic 2,4-D. In our present work, the $\mathrm{pH}$ of Andisols would favor the electrostatic interaction of 2,4-D-SOM because a fraction of neutral species will be present. For Ultisols, the unfavorable conditions for 2,4-D sorption was due to the higher negative net charge (Table 4).

The $1 / n_{\text {fads }}$ values were lower than one on the MET, FRE, STB, DIG, RAL soils, which correspond to L-type isotherms (Tables 3 and 7). These results indicate that the 2,4-D sorption first occurred on sorption sites of higher energy, followed by sorption sites of low energy. Table 7 shows a wide range of $K_{f o c}$ (17-704), indicating that 2,4-D sorption in the MET, FRE, STB, and RAL soils were not only by means of hydrophobic bonds on $O M$ (highest $K_{f o c}$ values, Table 7), but is also related to other inorganic soil constituents (Table 4) [48]. 
Pesticides with high $K_{o c}$ values $(\geq 1000)$ have been detected in groundwater and drainage water at several locations worldwide [55], being susceptible to leaching due to its weak sorption on the soil matrix. However, the variability in 2,4-D sorption in VADS is not only associated with $S O M$, because its soils have variable charge (Al/Fe oxides) than non-VADS $[55,58]$. In this regard, $K_{o c}$ is not appropriate to describe the potential leaching of 2,4-D in VADS.

For Ultisols, the predominance of more crystalline minerals (higher clay content) and lower OC content (Table 4) likely contributed to the global anionic 2,4-D sorption process. In this regard, if the ratio of mineral to $O C$ fraction is $>30$, the mineral blockage by $O C$ would be less, allowing the highest mineral contribution (ionic interaction is maximum) $[59,60]$. The contribution of crystalline clay minerals on Ultisols was significant (ratio between 15.3 to 30.5, Table 4) [48]. The dominant minerals in COLL and MET soils are kaolinite and halloysite, respectively (Table 4). The ionic interaction of 2,4-D in COLL soil should be unfavorable due to the net charge for kaolinite (IEP goes between $<3$ and 4 ) at the COLL's corresponding $p H$ (Table 4).

For DIG soil, the hysteresis coefficient $(H)$ was close to 1 (Table 7 ), suggesting the 2,4-D reincorporation to the soil solution in this soil. For the other VADS, the markedly irreversible sorption of 2,4-D ( $H$ close to 0 , Table 7 ) suggests that $2,4-\mathrm{D}$ reincorporation to the soil solution in VADS must be negligible. The degree of hysteresis depends on various factors related to the pesticides/soil properties and the prevailing conditions [61]. Sorption-desorption hysteresis has been explained as the result of: (i) irreversible binding or sequestration of solute to the $O C$ and/or clay mineral of soil aggregates (binding hysteresis) and (ii) entrapment of sorbed molecules in meso- and microporous structures within mineral structures and OC matrix of soil aggregates (structural hysteresis) [62] Although it is difficult to identify the relative contribution of binding and structural hysteresis to the total observed hysteresis on VADS, a contribution of both can be observed during 2,4-D desorption from Ultisols and Andisols according to the low $k_{\text {des }}$ values.

According to the IPD model for a pesticide, a longer time will take a strongly adsorbed pesticide to achieve the sorption equilibrium than one that is weakly adsorbed [63]. In this regard, 2,4-D presented the lowest $k_{2}$, highest $C_{1}$, and highest $K_{f}$ in RAL and NBR soils, implying that 2,4-D is retained on allophane surfaces and the OC matrix of these soil aggregates (Tables 5-7). The longest residence time of 2,4-D on RAL topsoil (lowest $k_{d e s}$ and $k_{s}$ values; Table 6 ) could increase its potential to leach into surface or groundwater in this kind of soil (high $H$ value; Table 7). 2,4-D presented the lowest $h$, highest $t_{1 / 2}$, and lowest $k_{s}$ values in Ultisols and DIG soil (Tables 5 and 6). For Ultisols, clay minerals and the lowest $O C$ content contributed to the highest $k_{2}$ values and lowest 2,4-D sorption.

The solute transport process is a function of the soil physical properties, chemical interaction between the solute and soil, and the advective velocity [64]. The 2,4-D transport on VADS should increase if these soils are previously subjected to conventional agriculture (adjustments of $p H_{\text {soil }}$ and heavy fertilizer $P$ applications). Andisols exhibit a positive charge under natural environmental conditions, especially when their original $p H$ range is acidic, requiring frequent adjustments of soil $p H$ and heavy fertilizer $P$ applications to remain productive. Our VADS have a strong capacity to retain $P$, but generally have low availability [21]. Such cases could result in the enhanced mobility of ionizable herbicides because it increases the competition by inorganic anions for positively charged sites and could alter the charge on the oxide surface, changing the speciation $[1,23,58,65]$.

The risk of groundwater contamination would be assumed to be high in fertilized VADS considering conditions of $p H$ alkaline due to the fertilizer $P$ applications, where 2,4-D could strongly compete with fertilizer $P$ for the same sorption sites. In general, weak acids and ionizable molecules dissociate to their anionic form as soil $p H$ increases, which the 2,4-D sorption decreases. In these conditions, anionic 2,4-D will have high mobility in water, quickly reaching aquatic ecosystems. Additionally, this risk would be assumed to be high in VADS subject to minimum tillage (conservation agriculture), increasing the use of herbicides due to the weed pressure. Consequently, the topsoil less disturbed will present: 
(i) a higher $O C$ content due to the $O M$ accumulation; this accumulation generally acidifies the topsoil, and this condition could increase 2,4-D sorption; and (ii) a higher hydraulic conductivity due to the greater continuity of vertically oriented macropores (transport pores) resulting from the wetting and drying process, root channels, and wormholes. The last point implies that 2,4-D moving down the soil profile should be quick due to preferential flow (nonequilibrium physical).

Therefore, the proper application of agricultural management on VADS is substantial to evaluate the risk of the contamination of groundwater since they will control the amount of herbicide available for vertical transport. In this sense, the 2,4-D sorption mechanism in VADS will depend on the 2,4-D form (ionic or molecular) and the soil physicochemical properties (such as $O M$, surface charge), where under several external conditions (agricultural management) it could contribute to the sorption of the anionic herbicide on VChS.

An overview of the reported $1 / n_{f a d s}, K_{d}, K_{f}$, and $K_{o c}$ values of 2,4-D for VChS and PChS is given in Table S4, showing significant variations in $K_{f}$ values between soils. In general, 2,4-D sorption in VChS and PChS was related to (i) solute parameters such as solubility in water and polarity and (ii) soil parameters such as $p H, O M$ (hydrophobic interactions and hydrogen bonding), and mineral content (hydrophilic mechanism on oxide surfaces through anion exchange) (Table $\mathrm{S} 4$ ). In some soils, $p H$ was found to have a positive correlation with 2,4-D sorption while in others, no correlation was observed. For a significant part of these studies, $K_{d}$ showed a positive correlation with OM content (Table S5). It was found that ligand exchange was the predominant 2,4-D sorption mechanisms in Andisol through the hydroxyl groups from metal-humic complexes and minerals such as allophane (Table S4).

For organic acid, the sorption mechanisms will depend on hydrophobic and hydrophilic sorption domains on VChS $[30,66]$, where these domains will be influenced by the quantity and quality of soil components (minerals and $O C$ ). Pesticides can be adsorbed on VADS through mineral (AlSi-Fe) and mineral-organic complexes (AlSi-Fe-HA (humic acids) (through hydroxyl or carbonyl groups of $H A$ from $O M$ ) [12]. Regarding the role of soil $O M$ quality, it has been reported that its humic matter fraction can be more important in determining the pesticide sorption parameters given the high reactivity of $H A$ [67]. Additionally, pesticides can be adsorbed by suspended sediment or colloidal matter (dissolved $O C(D O C))$ enhancing the pesticide leaching $[12,68]$. Finally, the present study agreed with the results observed in the review tables (Tables S3 and S4), like the presence of two stages of 2,4-D sorption controlled by EMT and found that the kinetic results fit broadly with the PSO model, and the isotherm studies fitted with the Freundlich model.

\subsection{Exploratory MLR Model of 2,4-D Sorption}

The 2,4-D $K_{f}$ values for VADS were positively correlated with the IEP of the soils (Figure 2). All the VADS presented an IEP value $<4$; the functional groups will be found as anionic species at the $p H$ of each soil and disfavor the ionic interaction with anionic 2,4-D. In other words, IEP values close to soil $p H$ tend to favor the 2,4-D sorption in VADS. Furthermore, in these soils, IEP negatively correlated with clay and clay/OC content. Different relationships between texture soil properties and soil constituents such as Fe oxides content were observed for VADS. For instance, $F e_{D C B}$ contents were significantly positively correlated with clay, clay/OC, and silt/OC, while those were negatively correlated with sand. Moreover, $F e_{P Y R O}$ contents were significantly negatively correlated with $C E C$ and $p H$ values. For VADS, the 2,4-D $K_{o c}$ values were positively correlated with $F e_{D C B}$ contents. Both the soil texture and the soil constituents can play an essential role in 2,4-D sorption in VADS. 


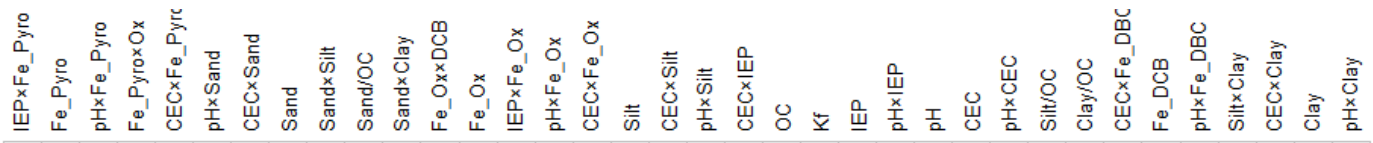

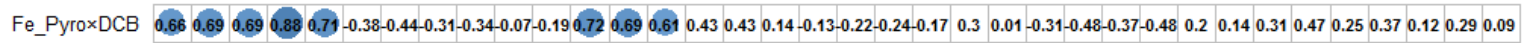
IEPxFe_Pyго $6.976 .950 .870 .890 .07-0.020 .26 \quad 0.26-0.06-0.020 .17 \quad 0.43 \quad 0.48 \quad 0.13 \quad 0.12-0.01-0.35-0.5 \quad-0.2 \quad 0.35 \quad 0.5 \quad 0.36-0.18-0.74-0.64-0.75-0.4-0.38-0.42-0.27-0.47-0.3-0.56-0.37-0.58$ Fe_Pyro $0.990 .870 .930 .01-0.080 .2 \quad 0.19-0.030 .030 .130 .390 .370 .07 \quad 0.07-0.08-0.42-0.6-0.370 .25 \quad 0.350 .16-0.37-0.78-0.67-0.79-0.32-0.27-0.44-0.26-0.47-0.18-0.41-0.2-0.44$ pH×Fe_Pyro $0.860 .910 .06-0.040 .240 .220 .03 \quad 0.110 .12 \quad 0.4 \quad 0.36 \quad 0.1 \quad 0.08-0.16-0.47-0.62-0.410 .18 \quad 0.32 \quad 0.11-0.38-0.72-0.67-0.76-0.3-0.24-0.42-0.25-0.45-0.2-0.39-0.18-0.4$

Fe_PyroxOx $\quad 0.91-0.17-0.23-0.07-0.07-0.23-0.190 .560 .770 .730 .490 .510 .17-0.08-0.26-0.070 .22 \quad 0.40 .25-0.18-0.59-0.34-0.5-0.28-0.29-0.050 .05-0.160 .06-0.19-0.08-0.29$

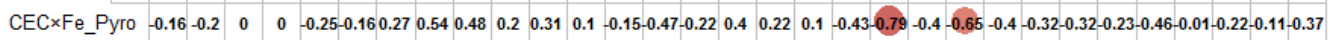
$\mathrm{pH} \times$ Sand $0.980 .960 .940 .60 .8-0.49-0.21-0.2-0.05-0.19-0.69-0.49-0.37-0.090 .050 .120 .030 .190 .35-0.080 .19-0.37-0.27-0.43-0.47-0.34-0.9-0.61-0.62-0.46$

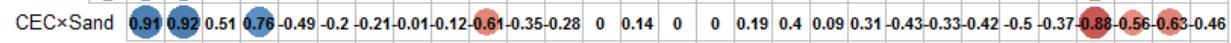
Sand $0.970 .590 .76-0.55-0.25-0.21-0.17-0.3-0.7-0.6-0.52-0.180 .120 .21 \quad 0.1 \quad 0.110 .13-0.29-0.05-0.41-0.31-0.58-0.56-0.49-0.95-0.72-0.67-0.57$ Sand $\times$ Silt $\quad 0.46 \quad 0.77-0.56-0.23-0.18-0.14-0.28-0.55-0.47-0.4-0.080 .24 \quad 0.150 .170 .160 .12-0.21-0.01-0.51-0.44-0.64-0.65-0.56-0.98-0.79-0.77-0.67$ Sand/OC $\quad 0.88-0.37-0.42-0.46-0.35-0.5-0.9-0.81-0.61-0.6-0.56-0.09-0.42-0.220 .28-0.4-0.080 .43 \quad 0.57-0.04 \quad 0.10 .17-0.39-0.080 .120 .23$ Sand $\times$ Clay $-0.52-0.35-0.45-0.23-0.38-0.9-0.73-0.58-0.52-0.33-0.25-0.43-0.2 \quad 0.33-0.230 .07 \quad 0.06 \quad 0.24-0.3-0.23-0.13-0.6-0.22-0.110 .02$

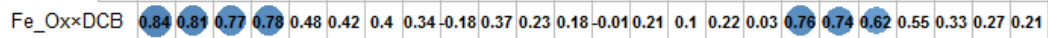

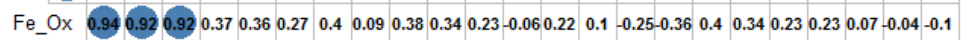
IEP xFe_Ox $0.860 .850 .480 .410 .380 .570 .22 \quad 0.56 \quad 0.620 .45-0.080 .150 .05-0.33-0.450 .340 .28 \quad 0.180 .12-0.12-0.22-0.26$ $\mathrm{pH} \times \mathrm{Fe}$-Ox $0.940 .310 .450 .480 .55-0.020 .290 .320 .450 .320 .460 .45-0.22-0.360 .51 \quad 0.380 .360 .16 \quad 0.12-0.07-0.02$ CECXFe_OX $0.43 \quad 0,610.47 \quad 0.6 \quad 0.17 \quad 0.16 \quad 0.26 \quad 0.31 \quad 0.17 \quad 0.57 \quad 0.43-0.28-0.370 .490 .32 \quad 0.28 \quad 0.27 \quad 0.22-0.02-0.02$ Silt $0.850 .730 .660 .460 .140 .510 .33-0.20 .36 \quad 0.09-0.21-0.390 .22 \quad 0.120 .06 \quad 0.450 .09-0.06-0.14$ CEC $\times$ Silt $\quad 0.850 .83 \quad 0.42-0.130 .33 \quad 0.41 \quad 0.2 \quad 0.790 .56-0.25-0.370 .360 .130 .16 \quad 0.4 \quad 0.28-0.04 \quad 0$

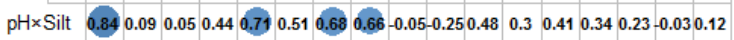
CEC×IEP $0.46 \quad 0.250 .710 .810 .36 \quad 0.66 \quad 0.58-0.45-0.570 .24 \quad 0 \quad 0.09-0.04-0.13-0.43-0.3$ OC $0.070 .470 .11-0.410 .19-0.09-0.84-0.76-0.58-0.71-0.75-0.36-0.5-0.64-0.74$ Kf $0.740 .5-0.17-0.42-0.33-0.17-0.350 .040 .120 .05-0.25-0.56-0.45-0.47$ IEP $0.79-0.07-0.06-0.06-0.5-0.65-0.11-0.16-0.15-0.32-0.62-0.67-0.64$ pH×IEP $0.56 \quad 0.32 \quad 0.49-0.29-0.440 .190 .05 \quad 0.2-0.26-0.33-0.5-0.28$ $\mathrm{pH} \quad 0.590 .890 .180 .150 .440 .280 .52-0.070 .240 .050 .36$ CEC 0.9-0.18-0.19 $0.4 \quad 0.110 .230 .210 .420 .040 .19$

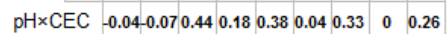
Silt/OC $\quad 0.920 .65 \quad 0.790 .780 .58 \quad 0.620 .780 .8$ Clay/OC $0.490 .630 .63 \quad 0.5 \quad 0.650 .830 .85$ CEC $\times F e \_D B C \quad 0.950 .960 .660 .670 .580 .66$ Fe_DCB 0.960 .680 .620 .660 .7 pH×Fe_DBC $0.6 \quad 0.630 .610 .73$ Silt×Clay $\quad 0.860 .850 .75$ CEC $\times$ Clay $\quad 0.920 .92$ Clay 0.95

Figure 2. Correlogram of VADS properties and sorption coefficients. Pearson correlation coefficients are proportional to color intensity and the size of the circle.

Different linear combinations of the soil physicochemical properties were evaluated to explain the 2,4-D sorption in VADS (Table S5). In this regard, soil descriptors or pairwise soil interactions $\left(I E P, F e_{D C B}, F e_{O x}, I E P \times F e_{P y r o}\right.$, Sand $\left.\times C l a y, p H \times F e_{D C B}, p H \times S i l t\right)$, with a value of inter-descriptor correlation coefficient lower than 0.6 , were selected for the model selection procedures. The pairwise interactions chosen were based on both the outcomes of correlogram of VADS properties and also the properties of soils (e.g., sand and clay interactions moderate the texture of the soil; IEP and $F e_{P Y R O}$ interactions moderate the surface charge of the soil), in order to increase the explanatory power of the model. In the descriptor selection process, the inclusion of pairwise predictor interactions resulted in 2,4-D sorption models with improved fits (Table S5) compared to models that only considered a single variable additive model. The model suggested in this study (Table S5; Equation (1)) is parsimonious and significant with an F-statistic of 8.193 , an $R^{2}$ of $0.80, R_{a d j}^{2}$ of 0.71 , and the lowest value of AIC, indicating that the model can be used in exploratory terms to assess the importance of soil descriptors on the 2,4-D sorption in VADS. This model can be used as a first approach to obtain a model for predictive purposes. Finally, the chosen subset of significant soil descriptors: $I E P, F e_{D C B}$, and $p H \times S i l t$; represent the 
most dominant properties of these soils that affect the 2,4-D sorption and explain the 2,4-D sorption mechanism in VADS.

\subsection{Spectroscopic Analysis}

\subsubsection{Raman Spectra}

The individual Raman spectra of 2,4-D and the NBR soil sample were recorded (Figure 3). The Raman spectrum of the NBR soil sample did not show important signals, and only a coherent spectral profile could be observed with the high content of $O M$ present in this type of soil (Figure 3). The Raman spectrum for 2,4-D crystals has been fully characterized and assigned. The most probable spectral assignment is presented in Table S6.

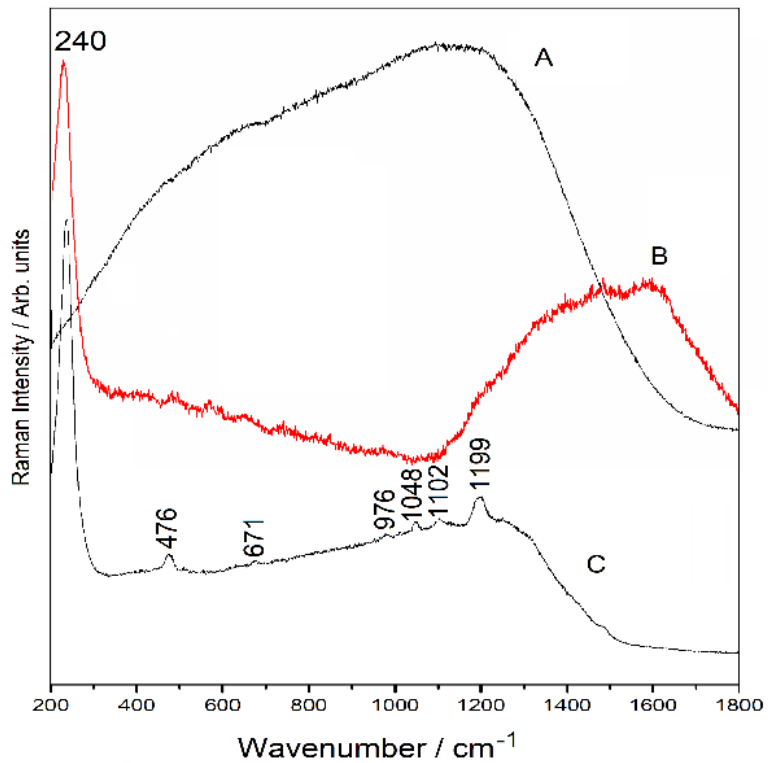

Figure 3. Raman and SERS Spectra of NBR soil sample and system 2,4-D/soil. A, Raman spectrum of NBR soil sample; B, SERS spectra of NBR soil sample; C, SERS spectra of 2,4-D/soil. The same methodology was used to obtain $B$ and $C$ spectra. Laser line 785 was used to record spectrum $A$ and laser line 633 for spectra B and C.

\subsubsection{SERS Spectra}

The interaction of 2,4-D with the NBR soil (Andisol) was evaluated according to the methodology reported here. The corresponding assignment of Raman and SERS bands was carried out first; these assignments are shown in Table S6. The main idea of this analysis was to evaluate and support the previous results regarding how 2,4-D interacts with the NBR soil. In this regard, it is possible to infer an essential interaction between the NBR soil and 2,4-D through the carboxylate group. In the SERS spectrum of 2,4-D interacting with the NBR soil, only signals attributed to the aromatic component of 2,4-D were observed; no signal of the carboxylate group was observed, which allowed us to infer that it is precisely the carboxylate group that holds 2,4-D bonded with the NBR soil (Figure 3). The SERS spectrum of 2,4-D-soil showed bands at 1199,671 , and $476 \mathrm{~cm}^{-1}$, which are assigned to $\mathrm{CH}$ deformations of the aromatic ring (Figure 3). On the other hand, a set of bands between 976 and $1102 \mathrm{~cm}^{-1}$ was mainly attributed to the aromatic ring's CC and CO stretching modes (Figure 3). The absence of this signal confirms that the carboxylate group directly drives the interaction of 2,4-D with the soil.

\section{Conclusions}

The PSO model well fits the 2,4-D sorption kinetics data on all VADS. Differences in the sorption extent for the fast and slow phases were observed through the IPD model where 2,4-D sorption kinetics was controlled by MT across the boundary layer and IOMD 
into macro- and micropores in VADS $\left(C_{1} \neq 0\right)$. Consequently, these types of soils provide time-dependent sorption sites $(F>1 \%)$. The higher $O C$ content and allophane govern the IPD in Andisols. The presence of kaolinite, halloysite, and Al/Fe oxides govern the IPD in Ultisols. The 2,4-D-VADS systems were classified within the zone of rapidly rising sorption $\left(0.1>R_{E}>0.02\right)$ and strong initial sorption $(R i<0.4)$. Equilibrium data, fitted by the Freundlich model, showed that the sorption irreversibility $(H \approx 0)$ was related to a chemisorption process that controls the initial sorption phase of 2,4-D in VADS. The spectroscopic results support the strong interaction of 2,4-D with the NBR soil, where the carboxylate group keeps it bound to the Andisol soil. This work suggests that the risk for 2,4-D leaching after application on macroporous soils (Andisols) may be increased, as was evidenced by its slow sorption even though 2,4-D is strongly adsorbed. Andisols used in our study are located in regions with high rainfall intensity, conditions that could facilitate its degradation and transport. Taken together, the slow 2,4-D sorption rate on VADS coupled with the low $F$ values highlight the need to consider specific mechanisms and sorption capacity when assessing groundwater contamination from VADS. Further research should focus on models to predict 2,4-D sorption in VADS with regulatory purposes. In this sense, this study allowed for the identification of an exploratory MLR model that emphasizes that $I E P, F e_{D C B}$, and $p H \times$ Silt are important soil descriptors in the 2,4-D sorption in VADS.

Supplementary Materials: The following are available online at https:/ / www.mdpi.com/article/10 .3390/ijerph18126264/s1, Table S1: Kinetic parameters predicted from pseudo-first-order, Dimensionless Elovich and Dimensionless Intraparticle Diffusion models, Table S2: Relationship between kinetic sorption, sorption parameters of 2,4-D and volcanic ash-derived soil properties, Table S3: 2,4-D sorption kinetic studies in variable-charge soils and permanent-charge soils, Table S4: 2,4-D sorption studies in variable-charge soils and permanent-charge soils, Table S5: Exploratory MLR models for 2,4-D sorption on volcanic ash-derived soils, Table S6: Experimental Raman and surface enhanced Raman scattering wavenumbers with relative intensities of 2,4-D and 2,4-D-NBR soil systems and the most probable band assignments, Figure S1: Plot for 2,4-D sorption on volcanic ash-derived soils.

Author Contributions: Conceptualization, L.C.-J. and M.E.; Methodology, L.C.-J., J.R.-B., C.G. and J.P.-R.; Software, L.C.-J., J.R.-B., J.P.-R. and V.D.-V.; Validation, L.C.-J., J.R.-B. and C.G.; Formal analysis, L.C.-J., J.R.-B., C.G., M.E., L.B., J.P.-R. and B.L.-A.; Investigation, L.C.-J.; Resources, L.C.-J., J.R.-B., C.G., M.E. and L.B.; Data curation, L.C.-J., J.R.-B., C.G., M.E., L.B, J.P.-R. and V.D.-V.; Writing—original draft preparation, L.C.-J.; Writing-review and editing, L.C.-J., J.R.-B., C.G., M.E., L.B. and B.L.-A.; Visualization, L.C.-J., J.R.-B., C.G. and V.D.-V.; Supervision, L.C.-J.; Project administration, L.C.-J.; Funding acquisition, L.C.-J. and J.R.-B. All authors have read and agreed to the published version of the manuscript.

Funding: This research was funded by DIUMCE 18-2019-PGI (Universidad Metropolitana de Ciencias de la Educación, Chile), FONDECYT 11110421 (CONICYT, Chile), FONDECYT-11100308 (CONICYT, Chile).

Institutional Review Board Statement: Not applicable.

Informed Consent Statement: Not applicable.

Data Availability Statement: The data that support the findings of this study are available from the corresponding author, upon reasonable request.

Acknowledgments: This work was supported through CEDENNA FB-0807 (CONICYT, Chile) and ANID—Millennium Science Initiative Program NCN17_040.

Conflicts of Interest: The authors declare no conflict of interest. The funders had no role in the design of the study; in the collection, analyses, or interpretation of data; in the writing of the manuscript, or in the decision to publish the results. 


\section{References}

1. Caceres-Jensen, L.; Rodríguez-Becerra, J.; Sierra-Rosales, P.; Escudey, M.; Valdebenito, J.; Neira-Albornoz, A.; Dominguez-Vera, V.; Villagra, C.A. Electrochemical method to study the environmental behavior of Glyphosate on volcanic soils: Proposal of adsorption-desorption and transport mechanisms. J. Hazard. Mater. 2019, 379, 120746. [CrossRef] [PubMed]

2. Gupta, M.; Garg, N.; Joshi, H.; Sharma, M. Persistence and mobility of 2,4-D in unsaturated soil zone under winter wheat crop in sub-tropical region of India. Agric. Ecosyst. Environ. 2012, 146, 60-72. [CrossRef]

3. Werner, D.; Garratt, J.A.; Pigott, G. Sorption of 2,4-D and other phenoxy herbicides to soil, organic matter, and minerals. J. Soils Sediments 2012, 13, 129-139. [CrossRef]

4. Ololade, I.A.; Alomaja, F.; Oladoja, N.A.; Ololade, O.O.; Oloye, F.F. Kinetics and isotherm analysis of 2,4-dichlorophenoxyl acetic acid adsorption onto soil components under oxic and anoxic conditions. J. Environ. Sci. Health Part B 2015, 50, 492-503. [CrossRef]

5. Johnson, W.G.; Lavy, T.L.; Gbur, E.E. Sorption, Mobility and Degradation of Triclopyr and 2,4-D on Four Soils. Weed Sci. 1995, 43, 678-684. [CrossRef]

6. $\quad$ Brusseau, M.L.; Famisan, G.B.; Artiola, J.F.; Janick, F.A.; Ian, L.P.; Mark, L.B. Chemical Contaminants. In Environmental Monitoring and Characterization; Academic Press: Burlington, VT, USA, 2004; pp. 299-312.

7. Dahlgren, R.A.; Saigusa, M.; Ugolini, F.C.; Donald, L.S. The Nature, Properties and Management of Volcanic Soils. In Advances in Agronomy; Academic Press: Cambridge, MA, USA, 2004; Volume 82, pp. 113-182.

8. Shoji, S.; Takahashi, T. Environmental and agricultural significance of volcanic ash soils. Glob. Environ. Res. $2002,6,113-135$.

9. Nanzyo, M.; Shoji, S.; Dahlgren, R. Physical Characteristics of Volcanic Ash Soils. In Developments in Soil Science; Shoji, S., Nanzyo, M., Dahlgren, R., Eds.; Elsevier: Amsterdam, The Netherlands, 1993; Chapter 7; pp. 189-207.

10. Shoji, S.; Nanzyo, M.; Dahlgren, R. Productivity and Utilization of Volcanic Ash Soils. In Developments in Soil Science; Shoji, S., Nanzyo, M., Dahlgren, R., Eds.; Elsevier: Amsterdam, The Netherlands, 1993; Chapter 8; pp. 209-251.

11. Ugolini, F.C.; Dahlgren, R.A. Soil development in volcanic ash. Glob. Environ. Res. 2002, 6, 69-81.

12. Caceres-Jensen, L.; Rodriguez-Becerra, J.; Escudey, M. Impact of Physical/Chemical Properties of Volcanic Ash-Derived Soils on Mechanisms Involved during Sorption of Ionisable and Non-Ionisable Herbicides. In Advanced Sorption Process Applications; Edebali, D.S., Ed.; IntechOpen: London, UK, 2018; pp. 95-149. [CrossRef]

13. Shinohara, H. Volcanic gases emitted during mild Strombolian activity of Villarrica volcano, Chile. Geophys. Res. Lett. 2005, 32, 1-5. [CrossRef]

14. Vergara, M.; López-Escobar, L.; Palma, J.; Hickey-Vargas, R.; Roeschmann, C. Late tertiary volcanic episodes in the area of the city of Santiago de Chile: New geochronological and geochemical data. J. S. Am. Earth Sci. 2004, 17, 227-238. [CrossRef]

15. Stern, C.R. Active Andean volcanism: Its geologic and tectonic setting. Revista Geológica Chile 2004, 31, 161-206. [CrossRef]

16. Rivera, A.; Bown, F.; Carrión, D.; Zenteno, P. Glacier responses to recent volcanic activity in Southern Chile. Environ. Res. Lett. 2012, 7, 014036. [CrossRef]

17. Lira, J.R.; Juica, W.G.; Thomas, C.V.; Canales, K.R.; Monetta, M.V.T.; Soto, R.T.; López, E.L.; Cornejo, I.F.; Moraga, P.R.; Meneses, F.I. Declaración de Ventas de Plaguicidas; Servicio Agrícola y Ganadero, División de Protección Agrícola, Subdepartamento de Plaguicidas y Fertilizantes: Santiago, Chile, 2006.

18. Borggaard, O.K.; Gimsing, A.L. Fate of glyphosate in soil and the possibility of leaching to ground and surface waters: A review. Pest Manag. Sci. 2008, 64, 441-456. [CrossRef]

19. Borie, G.; Peirano, P.; Zunino, H.; Aguilera, S.M. N-pool in volcanic ash-derived soils in Chile and its changes in deforested sites. Soil Biol. Biochem. 2002, 34, 1201-1206. [CrossRef]

20. Matus, F.; Garrido, E.; Sepúlveda, N.; Cárcamo, I.; Panichini, M.; Zagal, E. Relationship between extractable Al and organic C in volcanic soils of Chile. Geoderma 2008, 148, 180-188. [CrossRef]

21. Caceres-Jensen, L.; Neira-Albornoz, A.; Escudey, M. Herbicides Mechanisms Involved in the Sorption Kinetic of Ionisable and Non Ionisable Herbicides: Impact of Physical/Chemical Properties of Soils and Experimental Conditions. In Kinetic Modeling for Environmental Systems; Rahman, R.O.A., Ed.; IntechOpen: London, UK, 2019. [CrossRef]

22. Caceres-Jensen, L.; Escudey, M.; Fuentes, E.; Báez, M.E. Modeling the sorption kinetic of metsulfuron-methyl on Andisols and Ultisols volcanic ash-derived soils: Kinetics parameters and solute transport mechanisms. J. Hazard. Mater. 2010, 179, 795-803. [CrossRef]

23. Caceres-Jensen, L.; Rodriguez-Becerra, J.; Escudey, M.; Joo-Nagata, J.; Villagra, C.A.; Dominguez-Vera, V.; Neira-Albornoz, A.; Cornejo-Huentemilla, M. Nicosulfuron sorption kinetics and sorption/desorption on volcanic ash-derived soils: Proposal of sorption and transport mechanisms. J. Hazard. Mater. 2020, 385, 121576. [CrossRef]

24. Brusseau, M.; Rao, P. The influence of sorbate-organic matter interactions on sorption nonequilibrium. Chemosphere 1989, 18, 1691-1706. [CrossRef]

25. Allison, L.E. Organic Carbon. In Methods of Soil Analysis; American Society of Agronomy: Madison, WI, USA, 1965; pp. 1367-1396.

26. Blake, G.R. Particle Density. In Methods of Soil Analysis; Black, C.A., Ed.; American Society of Agronomy: Madison, WI, USA, 1965; Volume 9, pp. 371-373.

27. Pizarro, C.; Escudey, M.; Fabris, J.D. Influence of Organic Matter on the Iron Oxide Mineralogy of Volcanic Soils. Hyperfine Interact. 2003, 148, 53-59. [CrossRef]

28. Garrido, C.; Weiss-Lopez, B.E.; Vallette, M.M.C. Surface-enhanced Raman scattering activity of negatively charged bio-analytes from a modified silver colloid. Spectrosc. Lett. 2015, 49, 11-18. [CrossRef] 
29. Hiradate, S.; Furubayashi, A.; Uchida, N.; Fujii, Y. Adsorption of 2,4-Dichlorophenoxyacetic Acid by an Andosol. J. Environ. Qual. 2007, 36, 101-109. [CrossRef]

30. Hyun, S.; Lee, L.S. Quantifying the Contribution of Different Sorption Mechanisms for 2,4-Dichlorophenoxyacetic Acid Sorption by Several Variable-Charge Soils. Environ. Sci. Technol. 2005, 39, 2522-2528. [CrossRef]

31. Garrido, C.; Aguayo, T.; Clavijo, E.; Gómez-Jeria, J.S.; Campos-Vallette, M.M. The effect of the pH on the interaction of L-arginine with colloidal silver nanoparticles. A Raman and SERS study. J. Raman Spectrosc. 2013, 44, 1105-1110. [CrossRef]

32. Cáceres-Jensen, L.; Rodríguez-Becerra, J.; Parra-Rivero, J.; Escudey, M.; Barrientos, L.; Castro-Castillo, V. Sorption kinetics of diuron on volcanic ash derived soils. J. Hazard. Mater. 2013, 261, 602-613. [CrossRef]

33. Azizian, S. Kinetic models of sorption: A theoretical analysis. J. Colloid Interface Sci. 2004, 276, 47-52. [CrossRef]

34. Önal, Y. Kinetics of adsorption of dyes from aqueous solution using activated carbon prepared from waste apricot. J. Hazard. Mater. 2006, 137, 1719-1728. [CrossRef]

35. Wankasi, D.; Jnr, M.H.; Spiff, A.I. Sorption kinetics of $\mathrm{Pb}^{2+}$ and $\mathrm{Cu}^{2+}$ ions from aqueous solution by Nipah palm (Nypa fruticans Wurmb) shoot biomass. Electron. J. Biotechnol. 2006, 9, 587-592. [CrossRef]

36. Kumar, K.V.; Ramamurthi, V.; Sivanesan, S. Modeling the mechanism involved during the sorption of methylene blue onto fly ash. J. Colloid Interface Sci. 2005, 284, 14-21. [CrossRef] [PubMed]

37. Hameed, B.; El-Khaiary, M. Equilibrium, kinetics and mechanism of malachite green adsorption on activated carbon prepared from bamboo by $\mathrm{K}_{2} \mathrm{CO}_{3}$ activation and subsequent gasification with CO2. J. Hazard. Mater. 2008, 157, 344-351. [CrossRef] [PubMed]

38. Ruiz, B.; Cabrita, I.; Mestre, A.; Parra, J.; Pires, J.; Carvalho, A.; Ania, C. Surface heterogeneity effects of activated carbons on the kinetics of paracetamol removal from aqueous solution. Appl. Surf. Sci. 2010, 256, 5171-5175. [CrossRef]

39. Ho, Y. Review of second-order models for adsorption systems. J. Hazard. Mater. 2006, 136, 681-689. [CrossRef]

40. Fernández-Bayo, J.D.; Nogales, R.; Romero, E. Evaluation of the Sorption Process for Imidacloprid and Diuron in Eight Agricultural Soils from Southern Europe Using Various Kinetic Models. J. Agric. Food Chem. 2008, 56, 5266-5272. [CrossRef]

41. Rudzinski, W.; Panczyk, T. Kinetics of Isothermal Adsorption on Energetically Heterogeneous Solid Surfaces: A New Theoretical Description Based on the Statistical Rate Theory of Interfacial Transport. J. Phys. Chem. B 2000, 104, 9149-9162. [CrossRef]

42. Wu, F.-C.; Tseng, R.-L.; Juang, R.-S. Characteristics of Elovich equation used for the analysis of adsorption kinetics in dye-chitosan systems. Chem. Eng. J. 2009, 150, 366-373. [CrossRef]

43. Wu, F.-C.; Tseng, R.-L.; Juang, R.-S. Initial behavior of intraparticle diffusion model used in the description of adsorption kinetics. Chem. Eng. J. 2009, 153, 1-8. [CrossRef]

44. Inoue, M.H.; Oliveira, R.S.; Regitano, J.B.; Tormena, C.A.; Constantin, J.; Tornisielo, V.L. Sorption Kinetics of Atrazine and Diuron in Soils from Southern Brazil. J. Environ. Sci. Health Part B 2004, 39, 589-601. [CrossRef]

45. Nkedi-Kizza, P.; Shinde, D.; Savabi, M.R.; Ouyang, Y.; Nieves, L. Sorption Kinetics and Equilibria of Organic Pesticides in Carbonatic Soils from South Florida. J. Environ. Qual. 2006, 35, 268-276. [CrossRef]

46. Appel, J. Freundlich's adsorption isotherm. Surf. Sci. 1973, 39, 237-244. [CrossRef]

47. Sparks, D.L. Sorption Phenomena on Soils. In Environmental Soil Chemistry, 2nd ed.; Academic Press: Burlington, VT, USA, 2003; pp. 133-186.

48. Maqueda, C.; Undabeytia, T.; Villaverde, J.; Morillo, E. Behaviour of glyphosate in a reservoir and the surrounding agricultural soils. Sci. Total. Environ. 2017, 593-594, 787-795. [CrossRef]

49. Okada, E.; Costa, J.L.; Bedmar, F. Adsorption and mobility of glyphosate in different soils under no-till and conventional tillage. Geoderma 2016, 263, 78-85. [CrossRef]

50. Ioannou, Z.; Simitzis, J. Adsorption kinetics of phenol and 3-nitrophenol from aqueous solutions on conventional and novel carbons. J. Hazard. Mater. 2009, 171, 954-964. [CrossRef]

51. Tan, K.; Hameed, B. Insight into the adsorption kinetics models for the removal of contaminants from aqueous solutions. J. Taiwan Inst. Chem. Eng. 2017, 74, 25-48. [CrossRef]

52. Beltran, J.; Gerritse, R.G.; Hernandez, F. Effect of flow rate on the adsorption and desorption of glyphosate, simazine and atrazine in columns of sandy soils. Eur. J. Soil Sci. 1998, 49, 149-156. [CrossRef]

53. Paz-Y-Miño, C.; Sanchez, M.-E.; Arévalo, M.; Muñoz, M.J.; Witte, T.; De-La-Carrera, G.O.; Leone, P.E. Evaluation of DNA damage in an Ecuadorian population exposed to glyphosate. Genet. Mol. Biol. 2007, 30, 456-460. [CrossRef]

54. West, S.L.; White, G.N.; Deng, Y.; McInnes, K.J.; Juo, A.S.R.; Dixon, J.B. Kaolinite, Halloysite, and Iron Oxide Influence on Physical Behavior of Formulated Soils. Soil Sci. Soc. Am. J. 2004, 68, 1452-1460. [CrossRef]

55. Vereecken, H. Mobility and leaching of glyphosate: A review. Pest. Manag. Sci. 2005, 61, 1139-1151. [CrossRef]

56. Mella, A.; Kühne, A. Mapas Geológicos y Carta de Suelos, Mapa de Ubicación de los Suelos Derivados de Materiales Vocánicos, 1: 1.000. 000. In Suelos Volcánicos de Chile; Instituto de Investigaciones Agropecuarias (INIA): Santiago, Chile, 1985.

57. Kosmulski, M. pH-dependent surface charging and points of zero charge. IV. Update and new approach. J. Colloid Interface Sci. 2009, 337, 439-448. [CrossRef]

58. Cáceres-Jensen, L.; Gan, J.; Báez, M.; Fuentes, R.; Escudey, M. Adsorption of Glyphosate on Variable-Charge, Volcanic Ash-Derived Soils. J. Environ. Qual. 2009, 38, 1449-1457. [CrossRef]

59. Spadotto, C.A.; Hornsby, A.G. Soil sorption of acidic pesticides: Modeling pH effects. J. Environ. Qual. 2003, 32, 949-956. [CrossRef] 
60. Villaverde, J.; Kah, M.; Brown, C.D. Adsorption and degradation of four acidic herbicides in soils from southern Spain. Pest. Manag. Sci. 2008, 64, 703-710. [CrossRef]

61. Magga, Z.; Tzovolou, D.N.; Theodoropoulou, M.A.; Tsakiroglou, C.D. Combining experimental techniques with non-linear numerical models to assess the sorption of pesticides on soils. J. Contam. Hydrol. 2012, 129-130, 62-69. [CrossRef]

62. Wang, P.; Keller, A.A. Sorption and desorption of atrazine and diuron onto water dispersible soil primary size fractions. Water Res. 2009, 43, 1448-1456. [CrossRef] [PubMed]

63. Villaverde, J.; Van Beinum, W.; Beulke, S.; Brown, C.D. The Kinetics of Sorption by Retarded Diffusion into Soil Aggregate Pores. Environ. Sci. Technol. 2009, 43, 8227-8232. [CrossRef] [PubMed]

64. Brusseau, M.L. Factors influencing the transport and fate of contaminants in the subsurface. J. Hazard. Mater. 1992, 32, 137-143. [CrossRef]

65. Cáceres, L.; Fuentes, R.; Escudey, M.; Fuentes, E.; Báez, M.E. Metsulfuron-methyl Sorption/Desorption Behavior on Volcanic Ash-Derived Soils. Effect of Phosphate and pH. J. Agric. Food Chem. 2010, 58, 6864-6869. [CrossRef]

66. Hyun, S.; Lee, L.S. Factors Controlling Sorption of Prosulfuron by Variable-Charge Soils and Model Sorbents. J. Environ. Qual. 2004, 33, 1354-1361. [CrossRef]

67. Alister, C.; Araya, M.; Cordova, A.; Saavedra, J.; Kogan, M. Humic Substances and their Relation to Pesticide Sorption in Eight Volcanic Soils. Planta Daninha 2020, 38, 38. [CrossRef]

68. Worrall, F.; Parker, A.; Rae, J.E.; Johnson, A.C. A Study of Suspended and Colloidal Matter in the Leachate from Lysimeters and its Role in Pesticide Transport. J. Environ. Qual. 1999, 28, 595-604. [CrossRef] 